\title{
Cyclonic Eddies in the West Greenland Boundary Current System
}

\author{
Astrid Pacini, ${ }^{\mathrm{a}, \mathrm{b}}$ Robert S. Pickart, ${ }^{\mathrm{b}}$ Isabela A. Le Bras, ${ }^{\mathrm{b}, \mathrm{c}}$ Fiammetta Straneo, ${ }^{\mathrm{c}}$ \\ N. PENNy HOLliday, ${ }^{d}$ AND Michael A. SPAll ${ }^{b}$ \\ ${ }^{\text {a } M I T-W H O I}$ Joint Program in Physical Oceanography, Woods Hole, Massachusetts \\ ${ }^{\mathrm{b}}$ Woods Hole Oceanographic Institution, Woods Hole, Massachusetts \\ ${ }^{\mathrm{c}}$ Scripps Institution of Oceanography, University of California, San Diego, La Jolla, California \\ ${ }^{\mathrm{d}}$ National Oceanography Centre, Southampton, United Kingdom
}

(Manuscript received 27 October 2020, in final form 2 April 2021)

\begin{abstract}
The boundary current system in the Labrador Sea plays an integral role in modulating convection in the interior basin. Four years of mooring data from the eastern Labrador Sea reveal persistent mesoscale variability in the West Greenland boundary current. Between 2014 and 2018, 197 middepth intensified cyclones were identified that passed the array near the 2000-m isobath. In this study, we quantify these features and show that they are the downstream manifestation of Denmark Strait Overflow Water (DSOW) cyclones. A composite cyclone is constructed revealing an average radius of $9 \mathrm{~km}$, maximum azimuthal speed of $24 \mathrm{~cm} \mathrm{~s}^{-1}$, and a core propagation velocity of $27 \mathrm{~cm} \mathrm{~s}^{-1}$. The core propagation velocity is significantly smaller than upstream near Denmark Strait, allowing them to trap more water. The cyclones transport a 200-m-thick lens of dense water at the bottom of the water column and increase the transport of DSOW in the West Greenland boundary current by $17 \%$ relative to the background flow. Only a portion of the features generated at Denmark Strait make it to the Labrador Sea, implying that the remainder are shed into the interior Irminger Sea, are retroflected at Cape Farewell, or dissipate. A synoptic shipboard survey east of Cape Farewell, conducted in summer 2020, captured two of these features that shed further light on their structure and timing. This is the first time DSOW cyclones have been observed in the Labrador Sea-a discovery that could have important implications for interior stratification.
\end{abstract}

KEYWORDS: Boundary currents; Eddies; Transport

\section{Introduction}

The boundary current system encircling the Labrador Sea plays a pivotal role in the warm-to-cold water mass transformation that occurs in the sea, which contributes to the Atlantic meridional overturning circulation (AMOC). In the interior of the basin, newly ventilated Labrador Sea Water is formed through deep convection (e.g., Clarke and Gascard 1983; The Lab Sea Group 1998; Pickart et al. 2002). This weakly stratified water mass helps to maintain the hydrographic structure of the subpolar North Atlantic (Talley and McCartney 1982; Sy et al. 1997; Rhein et al. 2002) and serves to sequester carbon at depth (Takahashi et al. 2009; Khatiwala et al. 2013). The ability of the rim current to flux heat and freshwater into the interior basin (e.g., Pickart 1992; Lilly et al. 1999; Kawasaki and Hasumi 2014) modulates the convection by influencing both the preconditioning and restratification process (Katsman et al. 2004; Chanut et al. 2008).

Observations and models indicate that the overturning in depth and density space in the Labrador Sea are not collocated, though both are impacted by boundary current processes (Spall and Pickart 2001; Pickart et al. 2002; Spall 2004; Pickart and Spall 2007). While the deepest mixing occurs in the middle of the basin (Clarke and Gascard 1983), the diapycnal transformation there is impacted by eddies emanating from the boundary current that flux heat and freshwater to the interior (e.g., Lilly et al. 1999, 2003). At the same time, deep convection

Corresponding author: A. Pacini, apacini@whoi.edu can occur directly within the western boundary current of the Labrador Sea (Pickart et al. 2002). By contrast, the overturning in depth space is limited to the boundary. This is because planetary geostrophic dynamics limit the degree of sinking in the interior, while dissipation and eddy fluxes over the continental slope can allow such constraints to be broken (Spall 2010; Cessi and Wolfe 2013).

The boundary current system of the Labrador Sea, part of the cyclonic circulation of the subpolar gyre, is composed of several components. On the eastern side there is the West Greenland Coastal Current on the shelf (WGCC; e.g., Lin et al. 2018), the West Greenland Current (WGC) in the vicinity of the shelf break (e.g., Lazier and Wright 1993; Rykova et al. 2015), and the deep western boundary current at depth (DWBC; Dickson and Brown 1994) (Fig. 1). Part of the WGCC and WGC continue northward into Baffin Bay, while the remaining portion of these two components, along with the DWBC, flow cyclonically around the top of the basin to the Labrador side. There the flow is joined by the outflow from Baffin Bay. This consists of the Labrador Coastal Current and the Baffin Island Current near the shelf break, which merges with the recirculated WGC to form the Labrador Current.

A recent study of the West Greenland boundary current system, using four years of mooring data from the Overturning in the Subpolar North Atlantic Program (OSNAP) array west of Cape Farewell [Fig. 1; OSNAP West Greenland (WG)], quantified the different water masses and their transports (see Fig. 5 of Pacini et al. 2020). Altogether there are five water masses in the boundary current system (Fig. 2b), which vary in properties and transport on a seasonal basis. Cold and fresh 

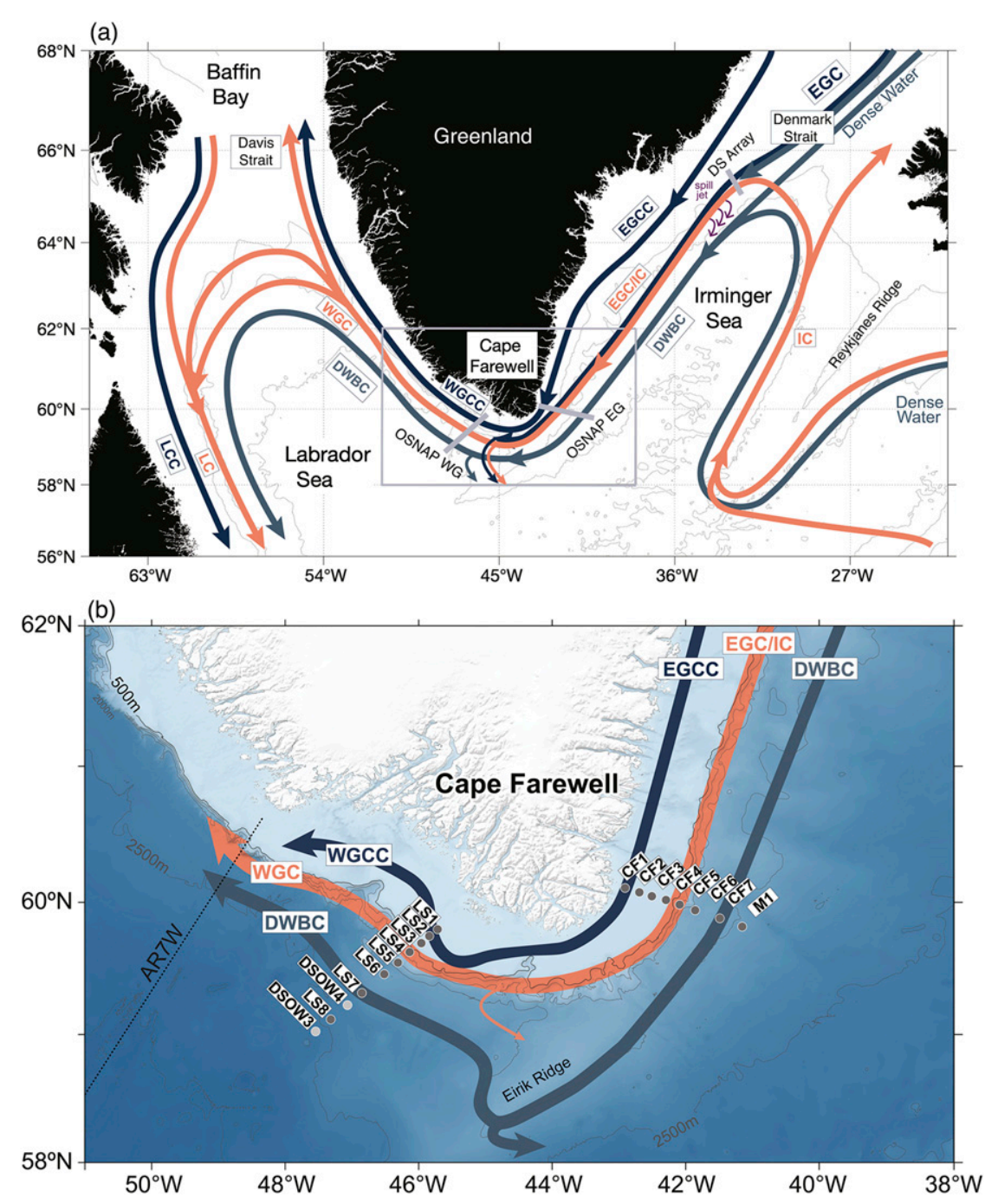

FIG. 1. (a) Irminger and Labrador Sea circulation schematic, with the OSNAP WG, OSNAP EG, and DS arrays labeled. Currents are labeled as follows: Irminger Current (IC); East Greenland Coastal Current (EGCC); East Greenland Current (EGC); deep western boundary current (DWBC); West Greenland Coastal Current (WGCC); West Greenland Current (WGC); Labrador Coastal Current (LCC); Labrador Current (LC). The red lines denote warm currents. (b) Zoomed-in schematic [gray box in (a)] of the circulation near Cape Farewell, Greenland, with the moorings of the OSNAP EG and OSNAP WG arrays labeled. The bathymetry is from ETOPO2.

Arctic-origin water and meltwater from Greenland combine to form Upper Polar Water (UPW; Rudels et al. 2002; Sutherland et al. 2009), which is found in the upper portion of the WGC as well as the WGCC. Labrador Sea Water (LSW), formed through wintertime convection in the Labrador and Irminger Seas, is found offshore of the boundary current and at the base of the WGC, with seasonally varying transport. Irminger Water (IW), a form of subpolar mode water, is found in the core of the WGC (between 400 and $600 \mathrm{~m}$ ), and its transport is inversely proportional to that of LSW (Pacini et al. 2020). In particular, when the transport of LSW is high (at the end of the convective winter period), the transport of IW is low. Conversely, when the transport of LSW is low (at the end of the summer), the transport of IW is high (Le Bras et al. 2020; Pacini et al. 2020).

The deep part of the boundary current system advects roughly equal amounts of Northeast Atlantic Deep Water (NEADW) and Denmark Strait Overflow Water (DSOW), both of which are important components of the AMOC (Dickson and Brown 1994). NEADW represents overflow waters emanating from the eastern part of the GreenlandScotland Ridge (Lee and Ellett 1965), and DSOW represents overflow waters emanating from the Denmark Strait (Dickson and Brown 1994; Tanhua et al. 2005; Hopkins et al. 2019). DSOW is denser, colder, and fresher than NEADW, and neither water mass exhibits seasonality in properties or 

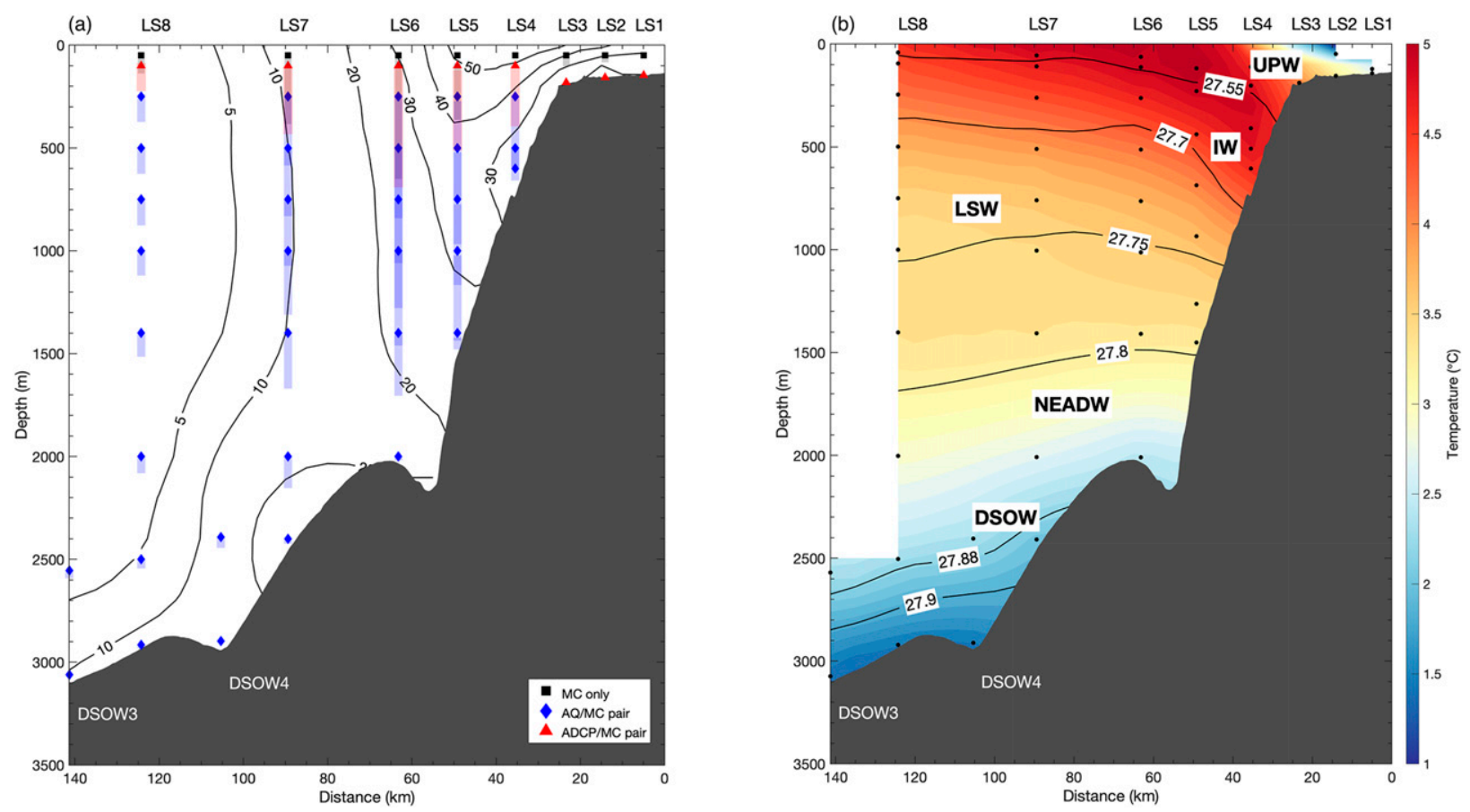

FIG. 2. (a) Instrumentation of the OSNAP WG mooring array. The nominal depths of the sensors are indicated by the solid symbols (see the legend), and the shading indicates the instrumentation blowdown ranges. MC indicates MicroCAT, AQ indicates Aquadopp, ADCP indicates acoustic Doppler current profiler. Black contours denote the 4-yr mean along-stream velocity $\left(\mathrm{cm} \mathrm{s}^{-1}\right)$ in the absence of eddy activity. The bathymetry is from the shipboard echosounder on R/V Knorr. (b) Mean vertical section of temperature (color; ${ }^{\circ} \mathrm{C}$ ) and isopycnals (contours; $\mathrm{kg} \mathrm{m}^{-3}$ ) in the absence of eddy activity. The locations of the five water masses discussed in the text are labeled.

transport. In the mean, the DWBC transports $5.5 \pm 0.5 \mathrm{~Sv}$ $\left(1 \mathrm{~Sv} \equiv 10^{6} \mathrm{~m}^{3} \mathrm{~s}^{-1}\right)$ of NEADW and $5.0 \pm 0.3 \mathrm{~Sv}$ of DSOW (where the uncertainty is the standard error; Pacini et al. 2020). It should be noted that overflow waters are typically defined as waters denser than $27.8 \mathrm{~kg} \mathrm{~m}^{-3}$ (Dickson and Brown 1994), but, as shown in Pacini et al. (2020), this definition excludes the upper portion of NEADW transport in the West Greenland boundary current. Using this historical definition, the overflow transport of the boundary current is underestimated by more than $2 \mathrm{~Sv}$.

The Labrador Sea has long been identified as a region with high eddy kinetic energy (e.g., Gascard and Clarke 1983; Lilly et al. 1999, 2003; Eden and Böning 2002; Prater 2002; Chanut et al. 2008). This has been demonstrated from moorings (Lilly et al. 1999; de Jong et al. 2014), drifting profilers and gliders (Prater 2002; Hátún et al. 2007; Frajka-Williams et al. 2009), surface altimetry (Heywood et al. 1994; Brandt et al. 2004), and modeling studies (Katsman et al. 2004; Gelderloos et al. 2011; de Jong et al. 2014; Rieck et al. 2019). The mesoscale variability has been divided into three main categories: 1 ) Irminger rings, which are large (30-60-km diameter) anticyclonic features shed from the WGC that carry warm, salty IW southwestward across the Labrador Sea (e.g., Lilly and Rhines 2002; Lilly et al. 2003; Hátún et al. 2007; de Jong et al. 2016). They are formed due to the interaction of the boundary current system with the steepening topography of the continental slope near $61^{\circ} \mathrm{N}$ (Eden and Böning 2002; Bracco and Pedlosky 2003; Wolfe and Cenedese 2006; Bracco et al. 2008). 2) Convective eddies, which are small-scale features (20-30-km diameter) formed via baroclinic instability of hydrographic fronts near sites of deep convection (Chanut et al. 2008). 3) Boundary current eddies, which arise due to baroclinic instability of the cyclonic boundary current as it flows around the basin (Chanut et al. 2008). Numerical sensitivity experiments have sought to diagnose the relative importance of these features in the transport of heat and freshwater to the convective region as well as their contribution to the stratification of the interior (e.g., Chanut et al. 2008; Gelderloos et al. 2011; Rieck et al. 2019). While results differ, it is clear that these features, in particular the Irminger rings and boundary current eddies, are important for regulating the strength of convection, the production of LSW in the Labrador Sea, and the restratification of the basin in spring/summer.

Upstream, along the east coast of Greenland, a fourth kind of eddy has been identified: middepth intensified DSOW cyclones. These are formed as the dense overflow from the Nordic Seas descends from the Denmark Strait into the Irminger Sea and stretches, thereby generating cyclonic vorticity (Spall and Price 1998). Similar features have been found due to cascading of dense shelf water in the northwestern Mediterranean Sea (Bosse et al. 2016). While these eddies arise from a steady outflow in the model of Spall and Price (1998), recent evidence suggests that their formation is triggered by mesoscale variability in the vicinity of the sill. Two dominant modes of variability have been identified in Denmark Strait, known as boluses and pulses, based on observations 
(von Appen et al. 2017; Mastropole et al. 2017) and models (Almansi et al. 2017). Both features are associated with increased DSOW transport through the sill (von Appen et al. 2017) and are formed by baroclinic instability of the hydrographic front between the warm northward-flowing water adjacent to Iceland and the cold southward-flowing water in the strait (Spall et al. 2019). von Appen et al. (2017) argue that boluses lead to strong DSOW cyclones downstream, while pulses result in weaker DSOW cyclones. Using a high-resolution numerical model, Almansi et al. (2020) found a one-to-one correspondence between boluses/pulses and the downstream cyclones.

Using data from a yearlong mooring array $280 \mathrm{~km}$ south of Demark Strait (Fig. 1a; DS array), von Appen et al. (2014) quantified the statistics of the DSOW cyclones and found that, on average, the features passed by the array every other day, most often near the $900-\mathrm{m}$ isobath. They propagate faster than the mean current and experience a vortex stretching of $40 \%$ as they descend from the sill to the array site. The self-propagation of these features is consistent with the topographic Rossby wave speed (Nof 1983; Pedlosky 2003), indicating that the selfpropagation of DSOW cyclones is due to the restoring force provided by potential vorticity gradients to a vortex column stretching (Spall and Price 1998; von Appen et al. 2014). Evidence from satellites indicates that they move offshore as they progress southward (Bruce 1995). Previously, the DSOW cyclones were thought to dissipate before reaching the southern tip of Greenland. However, during the initial deployment of the OSNAP mooring array east of Cape Farewell [Fig. 1; OSNAP East Greenland (EG)], shipboard measurements detected one of these features. Since then, the cyclones have been measured during subsequent OSNAP mooring recovery/deployment cruises, on both sides of Cape Farewell.

The extensive body of work on eddies of the Labrador Sea, described above, rarely documents instances of middepth intensified cyclonic features in the boundary current. This leads to questions such as the following: Do DSOW cyclones regularly progress around Cape Farewell? If so, how often and in what manner do they influence the boundary current and interior Labrador Sea? This study addresses these questions by first quantifying the statistics of cyclonic eddy presence in the OSNAP EG and OSNAP WG mooring arrays. Subsequently, a composite cyclone for the West Greenland boundary current is constructed, which highlights the relevant spatial and temporal scales associated with these features, as well as the azimuthal and core propagation velocities. The influence of the cyclones on the transport of the boundary current is then investigated, and, finally, a comparison with shipboard hydrographic data is presented. Together, this evidence reveals that DSOW cyclones are a ubiquitous feature of the Labrador Sea boundary current system and constitute the dominant source of subsurface mesoscale variability in the region near Cape Farewell.

\section{Data and methods}

\section{a. Mooring and shipboard data}

We focus on the OSNAP mooring array located on the West Greenland shelf and slope in the eastern Labrador Sea, to investigate cyclonic eddy activity (Fig. 1; OSNAP WG). The array was deployed in August 2014 and has been serviced every two years since then. It consists of 10 moorings: three bottom tripods on the shelf (LS1-LS3), five full-depth moorings (LS4-LS8), and two bottom-instrumented moorings (DSOW3-DSOW4). The moorings are spaced $\sim 15 \mathrm{~km}$ apart, with tighter station spacing on the shelf and larger distances off the shelf and slope. In this study, we use the first four years of data, from August 2014 to September 2018 (subsequent to 2018, more shelf tripods were added to the array). The instrumentation in the array consists of 49 Sea-Bird SBE37 MicroCATs that measure pressure, temperature, and conductivity; 33 Nortek Aquadopp current meters providing point measurements of velocity; and eight acoustic Doppler current profilers (RDI ADCPs, 300 and $75 \mathrm{kHz}$ ) that obtain vertical profiles of velocity (Fig. 2a).

Hourly vertical sections were constructed using LaplacianSpline interpolation (Smith and Wessel 1990). The gridded product has $100-\mathrm{m}$ vertical resolution and $5-\mathrm{km}$ horizontal resolution. The variables are potential temperature referenced to the sea surface (hereafter referred to as temperature), practical salinity, potential density referenced to the sea surface (hereafter referred to as density), and along-stream and crossstream velocity. The processing, data return, accuracy, and gridding are discussed in detail in Pacini et al. (2020). Overall, the data return and quality were excellent and provide hourly renderings of the boundary current system from August 2014 to September 2018. The velocity data were detided using the harmonic tidal routine T_TIDE (Pawlowicz et al. 2002), and then rotated such that the cross-stream velocity of the array was minimized. Positive along-stream velocity $u$ is directed toward the northwest $\left(318^{\circ} \mathrm{T}\right)$, and positive cross-stream velocity $v$ is directed offshore, toward the southwest $\left(228^{\circ} \mathrm{T}\right)$. Unless specified, the data presented in this study are from individual instrument time series. The gridded product is used to obtain transport estimates of the boundary current. Additionally, the gridded product is used to compute Ertel potential vorticity $\Pi$, defined as

$$
\Pi=\frac{f}{g} \frac{\partial b}{\partial z}-\frac{1}{g} \frac{\partial u}{\partial y} \frac{\partial b}{\partial z}+\frac{1}{g} \frac{\partial u}{\partial z} \frac{\partial b}{\partial y},
$$

where the buoyancy is $b=-g \rho / \rho_{o}, \rho$ is the density, $\rho_{o}$ is the reference density, the cross-shelf direction is $y$, and the vertical direction is $z$ (e.g., Pickart et al. 2005; Spall and Pedlosky 2008; Lin et al. 2018). This formulation neglects downstream variations, which cannot be measured with a two-dimensional array. We note, however, that assuming $\partial u / \partial y=-\partial v / \partial x$, as would be the case for a symmetric eddy, does not impact the results presented below. The value of $\Pi$ is smoothed using a $300-\mathrm{m}$ filter in the vertical and a 3-h temporal filter.

Additionally, the detided, nongridded data from the OSNAP EG moorings are used to compare cyclone statistics between the east and west sides of Cape Farewell. Details on the processing of these data, as well as the mean conditions and seasonality at the array site, can be found in Le Bras et al. (2018) and Hopkins et al. (2019). The detiding has been performed using the same harmonic tidal routine as the OSNAP WG data. 
LS8
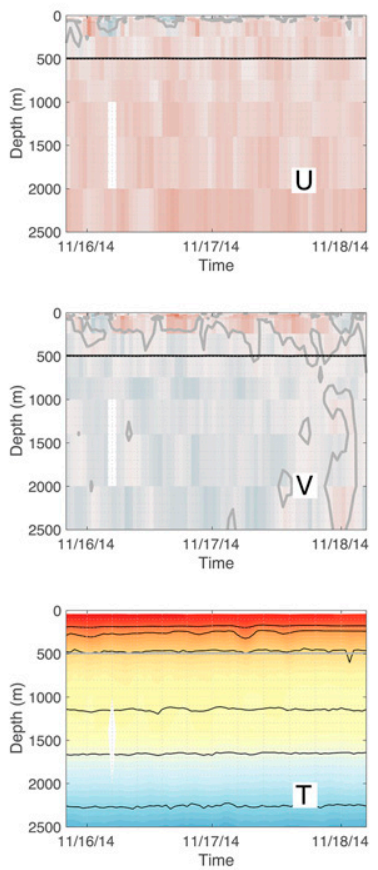

Load original data

Next timestep
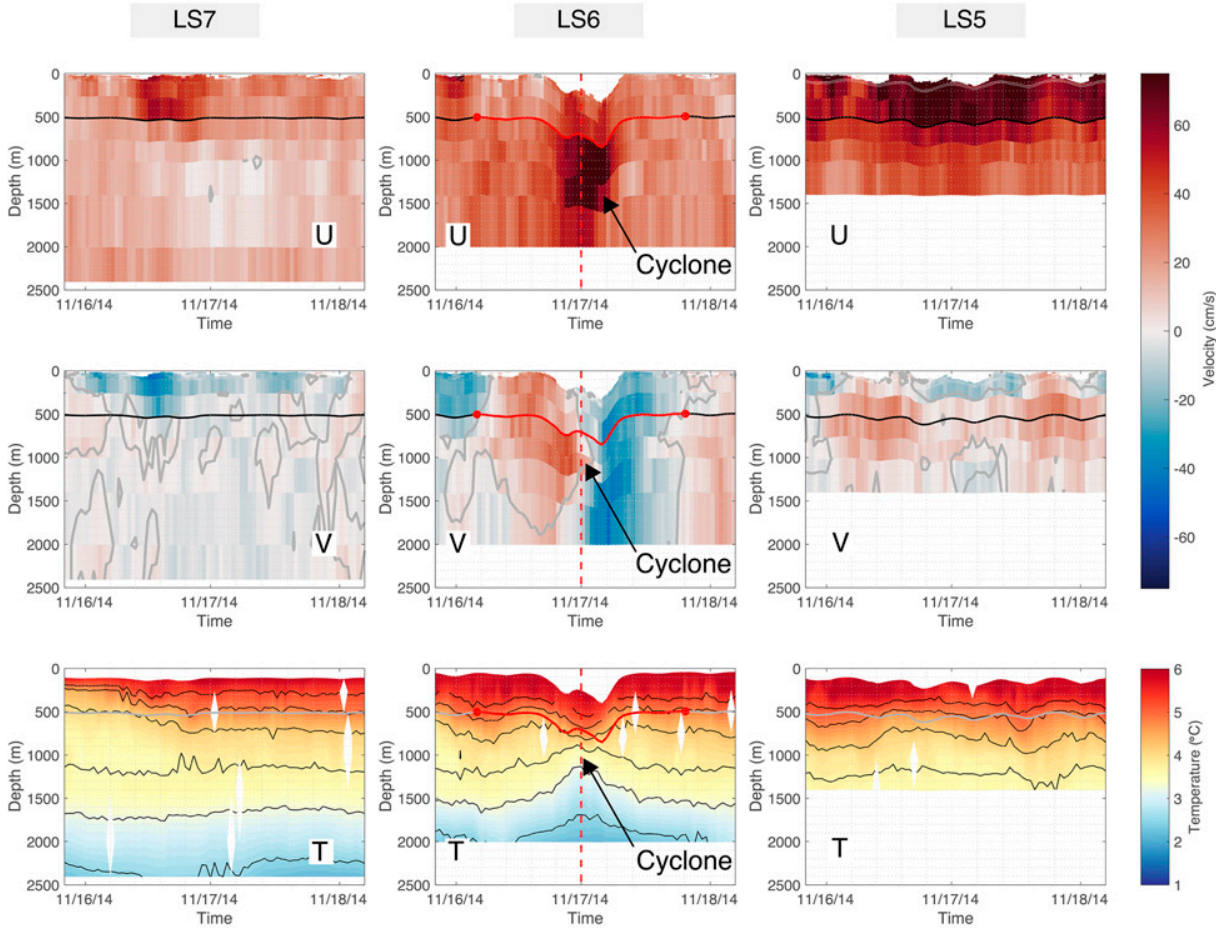

CYCLONIC

ANTICYCLONIC

DIPOLE

Click to select start of eddy, Cntrl + click to select end of eddy Shift + click to select center of eddy, Click on line to delete eddy

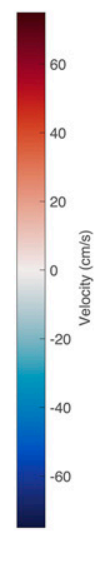

FIG. 3. Example of a cyclonic eddy at LS6 in the GUI on 17 Nov 2014. (top) Along-stream velocity, (middle) cross-stream velocity, and (bottom) temperature (color) with density contoured $\left(\mathrm{kg} \mathrm{m}^{-3}\right)$. The depth of the $500-\mathrm{m}$ instrument is plotted in each row (thick line) to highlight instrument blowdown. The user selects the start point, end point (filled circles), and center of feature (dashed line).

Last, shipboard hydrographic data are used from the OSNAP mooring servicing cruise in summer 2020 aboard the R/V Neil Armstrong from 23 June to 27 July. Conductivitytemperature-depth (CTD) casts were occupied using a SeaBird $911+$ mounted on a 24-position frame with 10-L Niskin bottles at $5-\mathrm{km}$ station spacing. Salinity samples were taken from the bottles to calibrate the conductivity sensors. The accuracy of the temperature and salinity measurements are estimated to be $0.001^{\circ} \mathrm{C}$ and 0.002 , respectively. Armstrong's hull-mounted Ocean Surveyor $38 \mathrm{-kHz}$ ADCP provided velocity profiles of the upper $1000 \mathrm{~m}$. Vertical sections were constructed in the same manner as for the mooring data. The hydrographic variables have a horizontal spacing of $3 \mathrm{~km}$ and vertical spacing of $5 \mathrm{~m}$, and the velocity data have a horizontal spacing of $5 \mathrm{~km}$ and vertical spacing of $30 \mathrm{~m}$.

\section{b. Eddy identification graphical user interface}

Following the method used by von Appen et al. (2014) to identify eddy variability at the DS array (Fig. 1), we designed and implemented a graphical user interface (GUI) to select instances of cyclonic and anticyclonic eddy activity, as well as the presence of dipole pairs. Only the cyclones are addressed in the present study. The anticyclones and dipole pairs are a dynamically distinct phenomenon and are being investigated in a separate study.
Dynamically, if the center of the feature passes close to a given mooring, the along-stream velocity is enhanced due to the core propagation speed of the eddy (the azimuthal flow is in the cross-stream direction in this case). If the eddy center passes offshore (onshore) of the mooring, the azimuthal flow enhances (reduces) the along-stream velocity. A feature must satisfy three criteria to be considered an eddy:

1) an intensification or reduction in the along-stream velocity;

2) a reversal in the cross-stream velocity (offshore to onshore for cyclonic; onshore to offshore for anticyclonic; offshore to onshore to offshore or vice versa for dipole pair); and

3) an increased presence of dense water in the bottom $500 \mathrm{~m}$ of the water column, as deduced from the temperature record and isopycnal displacements (discussed in more detail below).

An example of a cyclonic eddy passing by mooring LS6 is shown in Fig. 3 (details of these features are discussed in the results section below). The GUI displays time series of alongstream and cross-stream velocity as well as temperature at four different moorings, plotted over three days. The user selects the type of feature (cyclone, anticyclone, or dipole pair) and then chooses the start point, end point, and center time of the feature. In general, features only appeared at one mooring, meaning that the spacing of the mooring array was not sufficient 

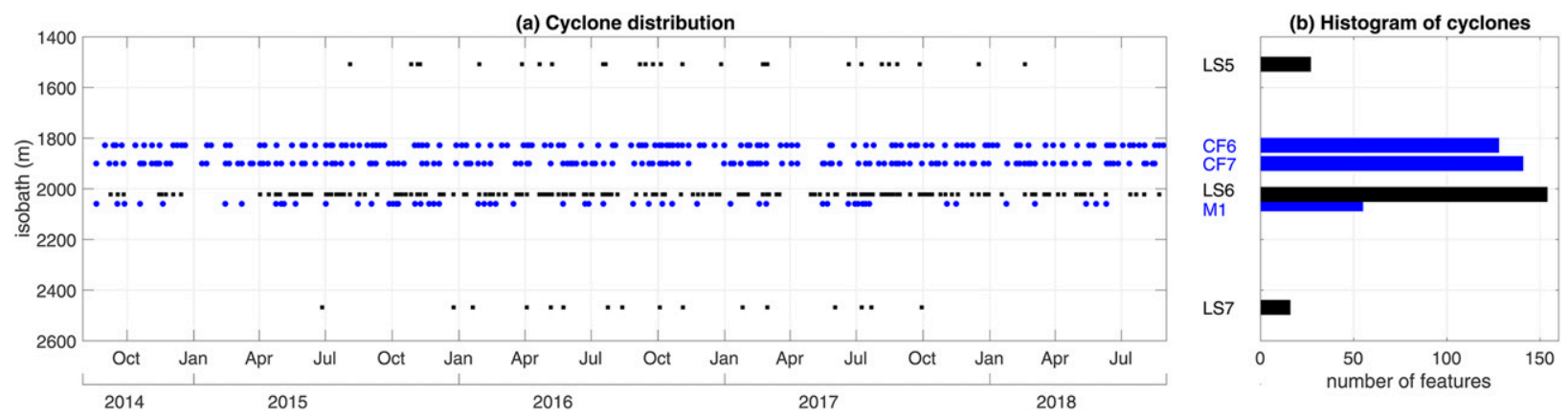

FIG. 4. (a) Statistics and lateral distribution of the cyclones, as determined from the GUI. Individual features are plotted as discrete symbols. The left axis is the isobath, and the right axis indicates the corresponding mooring (blue lettering for the OSNAP EG moorings; black lettering for the OSNAP WG moorings). (b) Histogram of identified cyclones per mooring.

to fully resolve the eddies. This indicates that the radius of the various features is smaller than the distance between moorings. However, the features typically have diameters close to $18 \mathrm{~km}$ [derived in section $3 \mathrm{~b}(3)$ ], while their cross-stream signals exhibit anomalously large values $\left(>10 \mathrm{~cm} \mathrm{~s}^{-1}\right)$ at diameters of up to $30 \mathrm{~km}$. At the EG array, the maximum spacing between moorings is $17 \mathrm{~km}(17 \mathrm{~km}$ between CF6 and CF7 and $16 \mathrm{~km}$ between $\mathrm{CF} 7$ and M1), and at the WG array, the maximum spacing between moorings is $26 \mathrm{~km}(14 \mathrm{~km}$ between LS5 and LS6 and $26 \mathrm{~km}$ between LS6 and LS7, see Fig. 2). Hence it is unlikely that an eddy would pass the mooring array (either EG or WG) without detection. The user can select more than one feature at a given time step (e.g., an anticyclone at LS5 and a cyclone at LS7).

Using the GUI, all four years of OSNAP WG and EG mooring data (2014-2018) were inspected and periods of eddy activity identified.

\section{Results}

\section{a. Statistics}

Using the GUI described in section $2 b$, all middepth cyclones were identified at the two arrays, revealing 324 features at OSNAP EG and 197 features at OSNAP WG. This translates into one cyclone every 4.5 days at EG and one cyclone every 7.6 days at WG. Assuming that the moorings do not miss features (see section $2 b$ ) and that all of the features originate at Denmark Strait [see section $3 b(2)$ ], this indicates that $60 \%$ of cyclones identified along East Greenland are also observed along West Greenland (Fig. 4). This reduction in the number of cyclones may be related to the observed loss in transport of the WGC and DWBC due to retroflection at Cape Farewell (Holliday et al. 2007, 2009).

There was no seasonality in the occurrence of the cyclones. At both arrays, the features were predominantly found offshore of the East Greenland Current (EGC)/WGC near the 2000-m isobath, at moorings CF6/CF7/M1 (EGC) and LS6 (WGC) (Figs. 4a,b). Feature tracking between the EG and WG arrays was attempted in order to connect the cyclones around Cape Farewell. We considered a range of core propagation speeds [discussed in more detail in section $3 b(3)$ ] to estimate when a given eddy sampled at OSNAP WG might have passed by the OSNAP EG array. However, it was impossible to match individual eddies at the two sites using this approach. At the OSNAP WG array, the focus of this study, cyclones typically take $70 \mathrm{~h}$ to transit past the mooring array, and, in total, instances of cyclonic activity account for $29 \%$ of the $4-y r$ mooring record as defined by the identification method described in section $2 b$.

\section{b. Cyclone characteristics}

\section{1) MODEL EDDY}

Of the 197 cyclones identified at OSNAP WG, 134 passed the array near LS6, which is located at the 2000-m isobath and is offshore of the main core of the WGC (Fig. 2). To create an unbiased composite feature, we identified all of the instances where the center of the cyclone passed close to LS6, and only these realizations were used in the average. This was done based on a criterion of double blowdown of the mooring and using a model eddy to test the sensitivity of this metric to a range of parameters.

When the center of an eddy passes close to the mooring, it blows the instrumentation down twice-once at the leading edge and once at the trailing edge-associated with the maximum offshore and onshore azimuthal velocity, respectively. By contrast, if an eddy passes onshore or offshore of the mooring, such that its center remains farther than the eddy radius away from the mooring location, it only blows the instrumentation down a single time, associated with the southward or northward azimuthal velocity. In our analysis, to be considered a centered feature, the eddy had to blow down the mooring's top float at $100 \mathrm{~m}$ to a depth of $240 \mathrm{~m}$ twice, with a rebound above $215 \mathrm{~m}$ between these maxima. Using a Gaussian model eddy, we can evaluate how successful this criterion is at capturing the centered features.

For a perfect Gaussian eddy, the azimuthal flow is given by

$$
v_{a}(r)=\frac{v_{o} r}{R_{o}} \exp \left\{0.5\left[1-\left(\frac{r}{R_{o}}\right)^{2}\right]\right\},
$$

where $R_{o}$ is the radius of maximum azimuthal velocity $v_{o}$, and $r$ indicates the distance from the center of the feature (Martin and Richards 2001). We prescribed the radius and azimuthal velocity of the model eddy to be $9 \mathrm{~km}$ and $24 \mathrm{~cm} \mathrm{~s}^{-1}$, respectively 

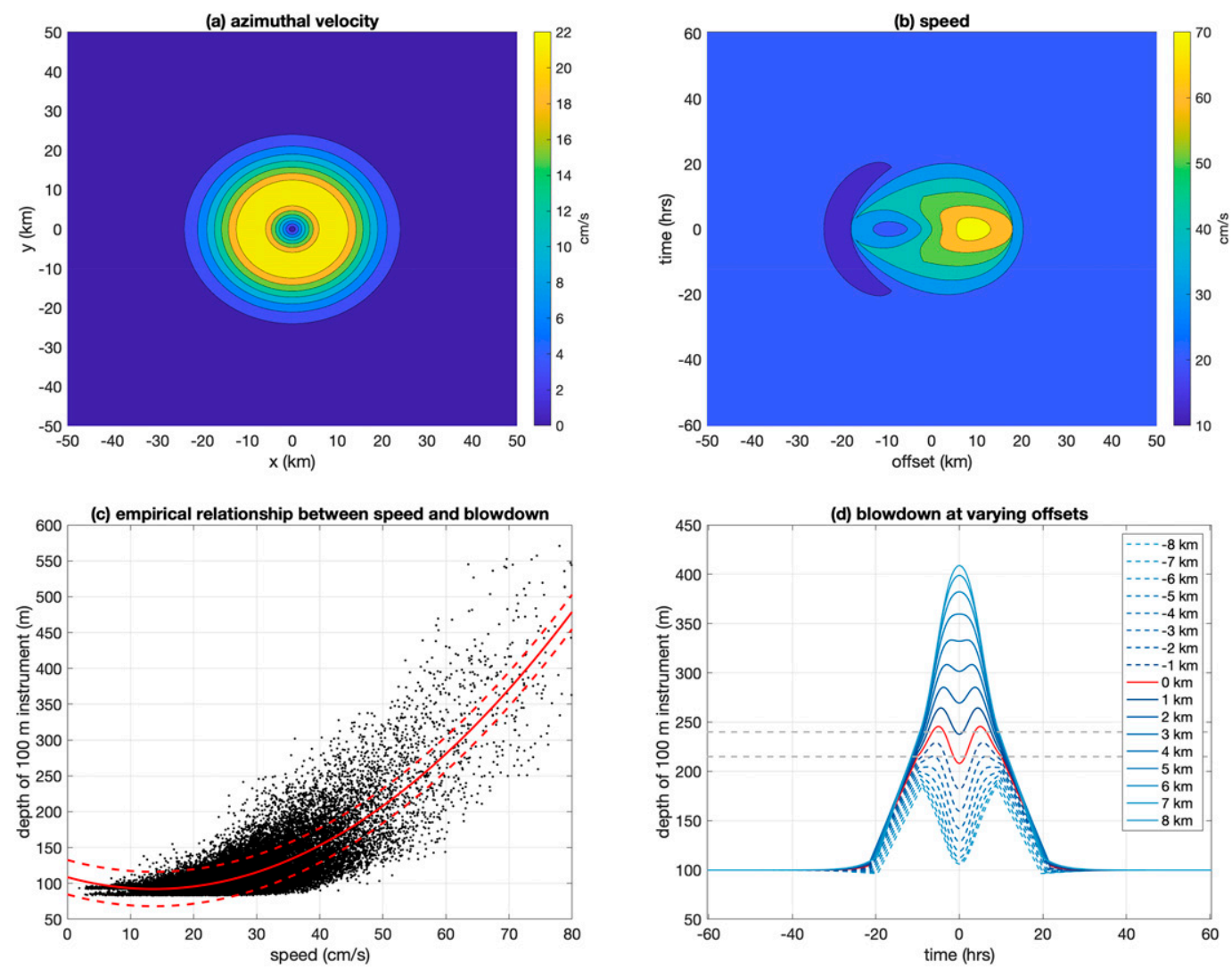

FIG. 5. Model Gaussian eddy (a) azimuthal speed and (b) speed as a function of offset and time (axis converted using $u_{b}+u_{c}$, described in the text). (c) Empirical relationship between blowdown depth of the LS6 mooring top float (nominally at $100 \mathrm{~m}$, in actuality, the first deployment was at $89 \mathrm{~m}$ and the second deployment was at $97 \mathrm{~m}$ ) and the speed sampled by the mooring. A quadratic fit is shown in red, and the standard deviation of the fit is indicated by the red dashed lines. (d) Blowdown as a function of offset and time, following the quadratic relationship in (c). Gray dashed lines indicate the thresholds the instruments must meet to be considered centered. The curve for zero offset is colored red. Positive (negative) offset indicate the onshore (offshore) side of the eddy.

(Fig. 5a). Next, a background velocity $u_{b}=23 \mathrm{~cm} \mathrm{~s}^{-1}$ was applied throughout the domain, and a propagation velocity $u_{c}=27 \mathrm{~cm} \mathrm{~s}^{-1}$ was imposed within the feature. These values are based on the mooring observations detailed below in sections $3 \mathrm{~b}(2)$ and $3 \mathrm{~b}(3)$. The three velocities, $u_{b}, u_{c}$, and $v_{a}$ were then used to calculate the along-stream and cross-stream velocity at each grid point according to the following equations,

$$
\begin{aligned}
& u(r, \theta)=u_{b}+u_{c}\left(r \leq 2 R_{o}\right)+v_{a}(r) \cos \theta, \text { and } \\
& v(r, \theta)=v_{a}(r) \sin \theta
\end{aligned}
$$

where $r=\sqrt{x^{2}+y^{2}}$ is the distance from the center of the feature, and $\theta$ is the angle measured clockwise from $y=0$ (von Appen et al. 2014). The $y$ axis is converted from distance to time utilizing $u_{b}+u_{c}$, which is necessary in order to compare the results of the model to the mooring time series. As shown in Fig. 5b, the projection of the azimuthal velocity onto the along-stream velocity at locations away from $x=0$ produces a resultant speed larger (smaller) than $u_{b}+u_{c}$ at locations onshore (offshore) of the center of the feature.
Subsequently, using the hourly mooring data, we derived a relationship between average speed measured by the mooring between 500 and $1500 \mathrm{~m}$ and the depth to which the mooring instrumentation was blown down. This relationship is quadratic and has previously been documented for other moorings (e.g., Hogg 1986, 1991). While the quadratic relationship is consistent among mooring arrays, the specific coefficients of the fit will vary as a function of mooring design. As shown in Fig. 5c, the quadratic fit to our mooring data is robust, with an $r^{2}$ of 0.7 , and provides a way to convert speed into blowdown depth for the model eddy. Doing so produces a map of blowdown as a function of time and offset from the center of the model eddy. Finally, we took slices through the feature at given offsets, where the resulting blowdown time series are shown in Fig. $5 \mathrm{~d}$. This reveals that only features sampled less than $1 \mathrm{~km}$ from their center meet the specified criterion (blowdown to $240 \mathrm{~m}$ twice, with a rebound to shallower than $215 \mathrm{~m}$ between the two). To gauge the uncertainty, we performed the same analysis using the upper and lower confidence bounds on the quadratic relationship in Fig. 5c, which indicate that only 

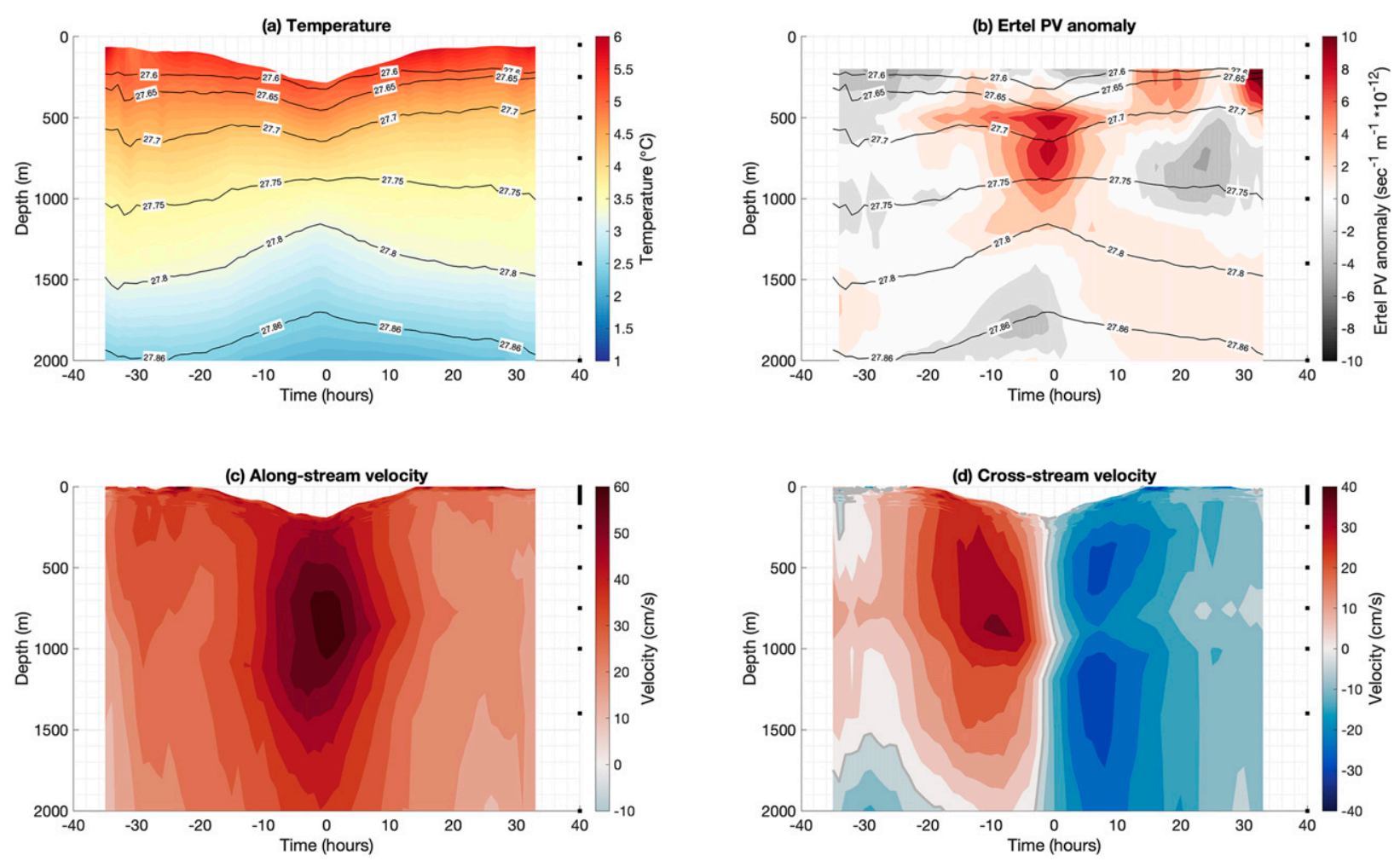

FIG. 6. Composite cyclone at LS6, composed of the 26 instances where the center of the feature passed less than $1 \mathrm{~km}$ to the mooring. The $x$ axis is time (in hours); 0 indicates the center of the eddy passage, negative time indicates the leading edge of the feature (time before center), and positive time indicates the trailing edge (time after center). The black squares on the right axis indicate the nominal instrument depths. (a) Temperature (color) overlain by density (contours; $\mathrm{kg} \mathrm{m}^{-3}$ ). (b) As in (a), but for Ertel potential vorticity anomaly (color; eddy PV - background PV in the absence of eddy activity). (c) Along-stream velocity. (d) Cross-stream velocity.

features sampled less than $2 \mathrm{~km}$ away from the center exhibit the blowdown signature described. This information is used below to compute error bounds on our eddy observations.

\section{2) COMPOSITE FEATURE}

Using the above blowdown criteria, we identified 26 features that passed by the array centered at LS6 (i.e., the eddy centers were within $1 \mathrm{~km}$ of the mooring). Since each of them took approximately $70 \mathrm{~h}$ to do so, as the core propagation velocity was similar [see Fig. 7a, described in section 3b(3)], no time normalization was necessary. Using the identified start, stop, and center points, these features were aligned, and a composite eddy was created. We note that the features do not exhibit significant differences between the OSNAP EG and WG lines, hence only the WG composite is presented.

As seen in Fig. 6, the cyclones are associated with middepth intensification of the along-stream and cross-stream flow, coincident with pinching of the isopycnals and anomalously high Ertel potential vorticity with respect to noneddy times. This region of high potential vorticity is the core of the eddy, bounded by the 27.65 and $27.8 \mathrm{~kg} \mathrm{~m}^{-3}$ isopycnals, and represents water that emanated from Denmark Strait (Spall and Price 1998) that became warmer and more saline due to entrainment downstream of the sill. Between the OSNAP EG and WG arrays, the $T / S$ properties of this density class remain consistent. Additionally, the features exhibit a lens of anomalously dense water in the bottom $800 \mathrm{~m}$ of the water column (note, for example, the $200-\mathrm{m}$ displacement of the $27.8 \mathrm{~kg} \mathrm{~m}^{-3}$ isopycnal). The along-stream velocity has a maximum, between 500 and $1000 \mathrm{~m}$, as the center of the feature passes by. The cross-stream velocity has a maximum directed offshore (onshore) approximately $10 \mathrm{~h}$ before (after) the center of the feature goes by.

The cross-stream velocity signature of the composite feature is not completely symmetric. In particular, at the leading edge of the cyclone there is a single core of maximum azimuthal velocity around $800 \mathrm{~m}$, while at the trailing edge, the feature has two cores of maximum velocity-one centered at $500 \mathrm{~m}$ and the second at $1200 \mathrm{~m}$ (Fig. 6d). This is true of 22 of the 26 features used to create the composite. It is important to note that this minimum in the azimuthal velocity is sampled by the instrumentation (i.e., it is not an artifact of interpolation), as the 750-m MicroCAT and Aquadopp are blown down during eddy passage to sample this minimum. One possible explanation for this asymmetry is due to the fact that the cyclones typically pass the mooring array at a different angle than that of the mean flow, hence part of the along-stream flow of the eddy is projected into the cross-stream direction. This enhances the azimuthal velocity on one side of the feature and reduces it on the other side, while also altering the vertical distribution of the 

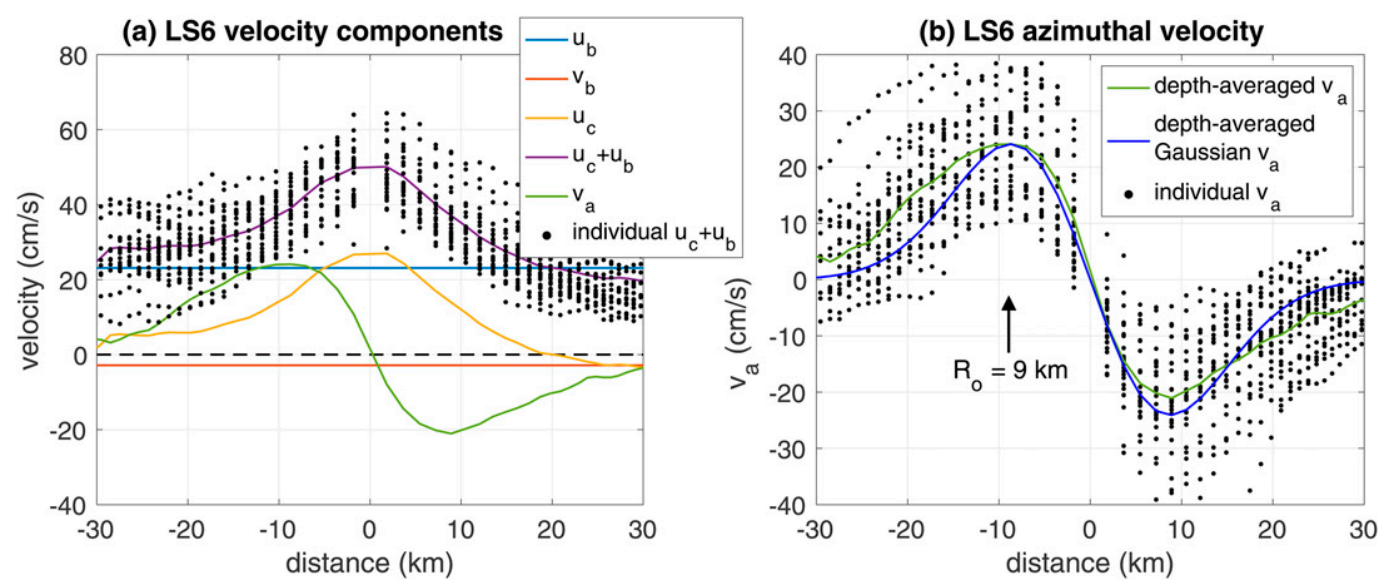

FIG. 7. (a) Decomposed depth-averaged velocity components for centered cyclones at LS6 (see the legend). (b) The azimuthal velocity from (a) (green curve) and the fitted perfect Gaussian (blue curve). The radius of maximum azimuthal flow $R_{o}$ is indicated. The black dots in (a) and (b) are the values of $u_{c}+u_{b}$ and $v_{a}$, respectively, from the individual eddies used to compute the composite feature.

velocity signal. We investigated this effect by constructing a series of composites where the along-stream velocity was taken to be directed at an angle with respect to the mean flow (for a range from $-15^{\circ}$ to $15^{\circ}$ off the direction of mean flow). However, this was not enough to explain the observed asymmetry. Another possibility is that the speed measured by the mooring, and thus the degree to which the instruments are blown down in the water column, is not symmetric over the course of the feature. This would lead to different sampling depths on either side of the feature, which could bias the results. While there were differences in some of the cases, overall the instrumentation blowdown was not significantly different on either side of the feature. As such, the asymmetry of the azimuthal flow structure of the eddies remains an open question.

\section{3) Velocity STRUCTURE}

Using the composite centered cyclone, we seek to decompose the flow field $(u, v)$ in order to determine the propagation speed and azimuthal speed of these features. For the following calculations, the time axis has been converted to a distance axis using the propagation speed derived below, and we consider the depth-averaged flow. Following von Appen et al. (2014), the flow is decomposed into

$$
\begin{aligned}
& u(x)=u_{b}+u_{c}(x), \text { and } \\
& v(x)=v_{b}+v_{a}(x),
\end{aligned}
$$

where $u_{b}$ and $v_{b}$ indicate the background along-stream and cross-stream velocity, in the absence of eddy activity (including anticyclonic and dipole activity), $u_{c}$ represents the alongstream propagation of the cyclones, and $v_{a}$ is the azimuthal flow of the eddy. The maximum of $u_{c}$ is the core propagation velocity, which represents the flow at which the volume of trapped water in the eddy moves along the slope. Given the ability of our criterion to identify centered features, the offset $(\theta)$ in Eqs. (3) and (4) is $90^{\circ}$ and thus the projection of the azimuthal velocity onto the along-stream direction can be neglected, resulting in the simplified formulation presented in Eqs. (5) and (6). The sum of the background flow and the core propagation velocity is the translation speed of the feature. We note that in von Appen et al. (2014) the moorings were spaced close enough together that the lateral structure of a feature could be described (i.e., cyclones were observed simultaneously at more than one mooring), but they did not resolve the depth structure due to moored CTD profiler failure during strong blowdowns. This allowed them to create a lateral composite eddy (in the $x-y$ plane), as opposed to the depth composite (in the $x-z$ plane) presented here.

Figure 7 a shows the components of depth-averaged flow in Eqs. (5) and (6), where the time axis has been transformed to a distance axis using the deduced translation speed, $u_{b}+u_{c}$. The background time- and depth-averaged along-stream velocity in the absence of eddies $\left(u_{b}\right)$ is on the order of $20 \mathrm{~cm} \mathrm{~s}^{-1}$, much larger than the background time- and depth-averaged crossstream velocity $\left(v_{b}\right)$, which is near zero. Subtracting $u_{b}$ from the composite along-stream velocity of the centered features (Fig. 6c) gives the propagation velocity of the cyclone $u_{c}(x)$. This reaches a maximum of $27 \pm 8 \mathrm{~cm} \mathrm{~s}^{-1}$ at the center of the feature (the core propagation velocity), then returns to near zero outside of the core radius of the eddy. In the region outside of the core, $u_{c}$ reflects the dynamically induced circulation due to the translation of the eddy. A similar $u_{c}(x)$ profile is obtained when doing the analogous calculation at mooring LS5 $\left(u_{c, \text { max }}=30 \mathrm{~cm} \mathrm{~s}^{-1}\right)$ and LS7 $\left(u_{c, \text { max }}=35 \mathrm{~cm} \mathrm{~s}^{-1}\right)$. It should be noted, however, that only one feature passed centered at LS5 and one at LS7. Subtracting $v_{b}$ from the composite crossstream velocity of the centered features (Fig. 6d) gives the azimuthal flow of the cyclone $v_{a}(x)$. This reveals a maximum azimuthal velocity of $24 \pm 0.6 \mathrm{~cm} \mathrm{~s}^{-1}$ at a radius of $9 \pm 1 \mathrm{~km}$ $\left(21 \mathrm{~cm} \mathrm{~s}^{-1}\right.$ at $6 \mathrm{~km}$ for LS5; $25 \mathrm{~cm} \mathrm{~s}^{-1}$ at $12 \mathrm{~km}$ for LS7). Additionally, included in Figs. $7 \mathrm{a}$ and $7 \mathrm{~b}$ are the depth-averaged velocity profiles for each of the 26 cyclones that constitute the composite feature. Table 1 presents the derived velocities for 
TABLE 1. Composite properties and statistical average and standard deviation for the 26 centered eddies.

\begin{tabular}{|c|c|c|c|c|c|c|}
\hline & $\begin{array}{l}\text { Total along-stream flow } \\
u_{b}+u_{c, \max }\left(\mathrm{cm} \mathrm{s}^{-1}\right)\end{array}$ & $\begin{array}{l}\text { Core propagation velocity } \\
\qquad u_{c, \max }\left(\mathrm{cm} \mathrm{s}^{-1}\right)\end{array}$ & $\begin{array}{l}\text { Azimuthal speed } \\
v_{a, \max }\left(\mathrm{cm} \mathrm{s}^{-1}\right)\end{array}$ & $\begin{array}{l}\text { Radius } \\
R_{o}(\mathrm{~km})\end{array}$ & $\begin{array}{c}\text { DSOW } \\
\text { transport (Sv) }\end{array}$ & $\begin{array}{l}\text { Rossby } \\
\text { number }\end{array}$ \\
\hline Com & $51 \pm$ & $27 \pm 8$ & $24 \pm 0.6$ & $9 \pm 1$ & & 0.44 \\
\hline Individual cyclones & $51 \pm 7$ & $28 \pm 7$ & $30 \pm 8$ & $10 \pm 5$ & $5.5 \pm 1.7$ & $0.62 \pm 0.3$ \\
\hline
\end{tabular}

the composite cyclone, as well as the average and standard deviation of these properties for the 26 individual features that make up the composite. As these statistics reveal, the derived properties $\left(u_{c, \max }, v_{a, \max }\right.$, and $\left.R_{o}\right)$ are consistent between the composite and the average of the individual features.

Returning to the perfect Gaussian eddy introduced in Eq. (2), we take $R_{o}$ to be $9 \mathrm{~km}$ and $v_{o}$ to be $24 \mathrm{~cm} \mathrm{~s}^{-1}$, based on the composite at LS6 (Fig. 7a). The resulting azimuthal flow of the perfect Gaussian eddy shows excellent agreement with the data (cf. the blue and green curves in Fig. 7b). The value of $R_{o}$ (for each of the moorings) is consistent with the fact that the cyclones were only detected at a single site; that is, their radii are smaller than the mooring spacing $(\sim 15 \mathrm{~km})$. Using both the composite feature and the individual features, Rossby numbers are found to lie between 0.4 and 0.6 , indicating that the cyclostrophic effects are important and the centrifugal term impacts the velocity structure within the features (e.g., McWilliams 1985).

The derived core propagation velocity of these cyclonic features $\left(27 \mathrm{~cm} \mathrm{~s}^{-1}\right)$ can be compared to that of a topographic Rossby wave in the long-wave, linear limit,

$$
c=\frac{g^{\prime}}{f} \frac{d H}{d y},
$$

where $g^{\prime}$ is the reduced gravity and $d H / d y$ is the topographic slope (Nof 1983; Pedlosky 2003). Using the mooring and shipboard echosounder data, respectively, to determine values of $g^{\prime}\left(9.5 \times 10^{-4} \mathrm{~m} \mathrm{~s}^{-2}\right.$, calculated using a layerwise approximation near the $27.75 \mathrm{~kg} \mathrm{~m}^{-3}$ isopycnal) and $d H / d y(0.03)$, a Rossby wave propagation of $23 \mathrm{~cm} \mathrm{~s}^{-1}$ is estimated. This compares well with the observed core propagation velocity of the cyclones.

It is enlightening to compare these derived eddy properties to those discussed in von Appen et al. (2014) for DSOW cyclones $280 \mathrm{~km}$ south of Denmark Strait. Using their mooring data (Fig. 1; DS array), von Appen et al. (2014) diagnosed a mean radius $R_{o}$ of $7.8 \mathrm{~km}$, a maximum azimuthal velocity of $22 \mathrm{~cm} \mathrm{~s}^{-1}$, and an eddy core propagation velocity of $45 \mathrm{~cm} \mathrm{~s}^{-1}$. While the first two estimates are very similar to the values deduced here $\left(9 \mathrm{~km}\right.$ and $24 \mathrm{~cm} \mathrm{~s}^{-1}$, respectively), the core propagation velocity near Cape Farewell is significantly slower $\left(27 \mathrm{~cm} \mathrm{~s}^{-1}\right)$. This is important because at the DS array the cyclones are less able to kinematically trap water, that is, $u_{c, \max }>$ $v_{a \text {, max }}$ (Flierl 1981). By contrast, one sees in Fig. 7a that $u_{c \text {, max }}$ is comparable to $v_{a \text {, max }}$ at the WG array. This suggests that, as the features progress southward, they slow to the point where they may be able to trap water in a wider radius. However, in both regions the water mass at the core of the eddies must be translated with the features since it is this high potential vorticity water that is responsible for the eddy itself. We note that both the translational speed and azimuthal flow of the (a)

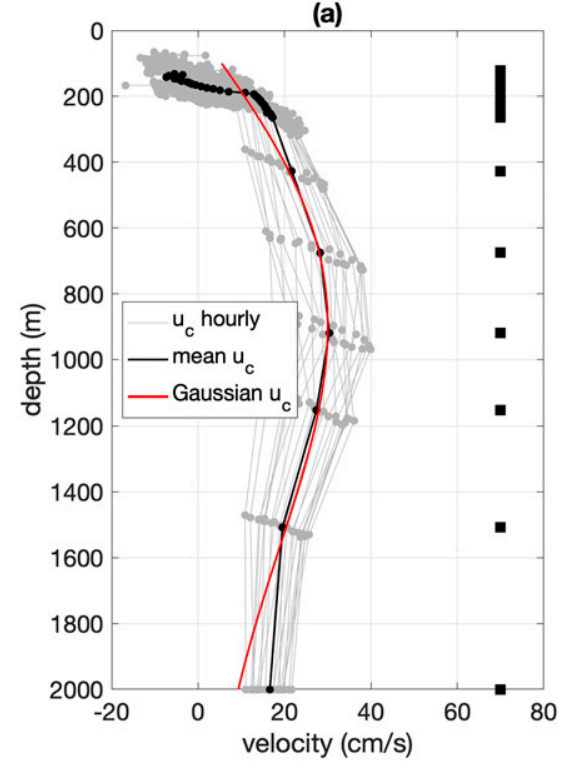

(b)

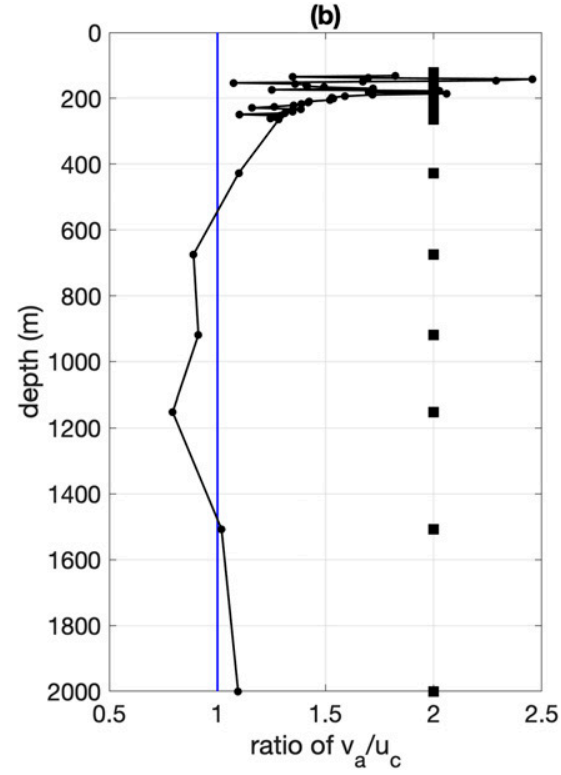

FIG. 8. Depth-dependent velocity structure of composite cyclone. (a) Depth-dependent profiles of $u_{c}$ from $10 \mathrm{~h}$ before to $10 \mathrm{~h}$ after the center of the feature (gray lines), average profile of $u_{c}$ during this 20-h period (black line), and the Gaussian fit to the depth-dependent $u_{c}$ (red line). Black squares indicate mean instrument depths. (b) Depth-dependent ratio of $v_{a} / u_{c}$. 

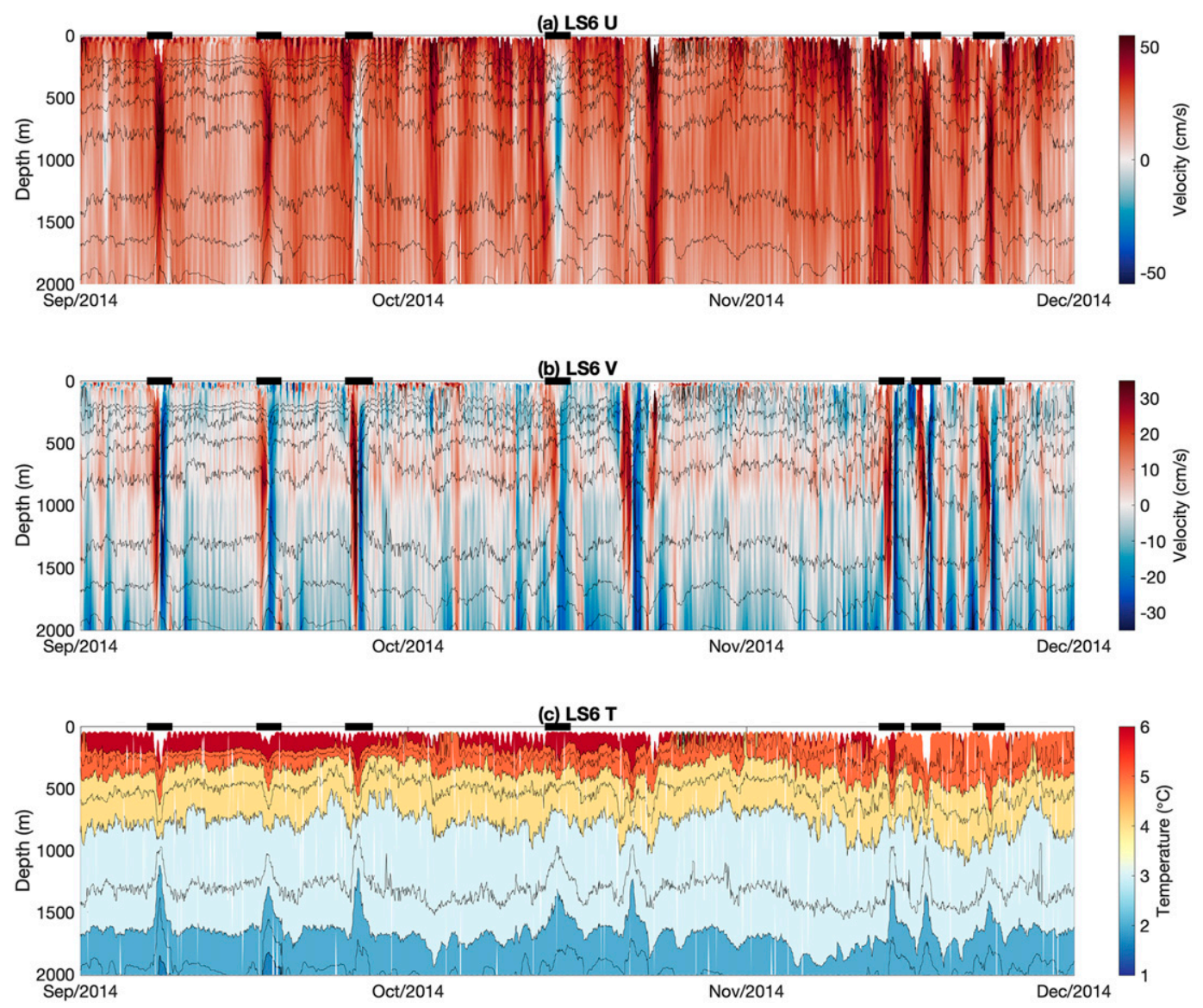

FIG. 9. Depth-time plot of (a) along-stream velocity, (b) cross-stream velocity, and (c) potential temperature. Potential temperature is contoured, with identified cyclones at LS6 denoted by the black bars along the top, for September-November 2014. The feature on 22 Oct, not identified as a cyclone, was a dipole pair.

composite eddy are depth dependent (Figs. 6c,d). However, the background velocity is also depth dependent, such that the vertical profile of $u_{c, \text { max }} / v_{a, \text { max }}$ remains of order one versus depth (Fig. 8). Hence, water can be trapped throughout the water column, including the DSOW in the bottom layer.

Using the vertical profiles of velocity obtained from the observations, we extended the formulation of the model eddy in section $3 \mathrm{~b}(1)$ so that it varies with depth. To do so, we fit a Gaussian to the vertical profiles of $u_{c}$ and $v_{a}$, and applied a linear fit to the vertical profile of $u_{b}$ (see Fig. 8a for the Gaussian fit to $u_{c}$ ). In the reference frame moving with the eddy, the streamlines were then computed at different depths. Closed streamlines represent regions where fluid can be trapped, and our calculation revealed that the model cyclone traps water at all depths below $400 \mathrm{~m}$, with a maximum trapping radius of $20 \mathrm{~km}$ from the center at 900-m depth. This further demonstrates that these features can trap water throughout much of the water column.

\section{c. Influence on transport}

We now investigate the impact of the cyclones on the transport of the boundary current system. The OSNAP WG array measures all of the components of the West Greenland boundary current, as well as an offshore cyclonic recirculation gyre (Pacini et al. 2020). The division between the boundary current regime and the gyre can be defined as the contour of $10 \%$ of the maximum boundary current velocity, which on average is the $8 \mathrm{~cm} \mathrm{~s}^{-1}$ contour (Pickart and Spall 2007; Pacini et al. 2020). Using this criterion, Pacini et al. (2020) calculated a total boundary current transport of $29.9 \pm 0.3 \mathrm{~Sv}$ and a

TABLE 2. Four-year mean transports for the different components of the West Greenland boundary current system, with standard error.

\begin{tabular}{lcccc}
\hline \hline & Total (Sv) & Without all cyclones (Sv) & Only centered cyclones (Sv) & Difference (Sv) \\
\hline Total & $29.9 \pm 0.3$ & $29.7 \pm 0.4$ & $32.5 \pm 0.7$ & 2.8 \\
NEADW & $5.5 \pm 0.5$ & $5.5 \pm 0.4$ & $6.6 \pm 0.4$ & 1.1 \\
DSOW & $5.0 \pm 0.3$ & $4.7 \pm 0.3$ & $5.5 \pm 0.3$ & 0.8 \\
$\sigma_{\theta}>27.8 \mathrm{~kg} \mathrm{~m}^{-3}$ & $8.3 \pm 0.2$ & $8.0 \pm 0.2$ & $9.4 \pm 0.2$ & 1.4 \\
\hline
\end{tabular}



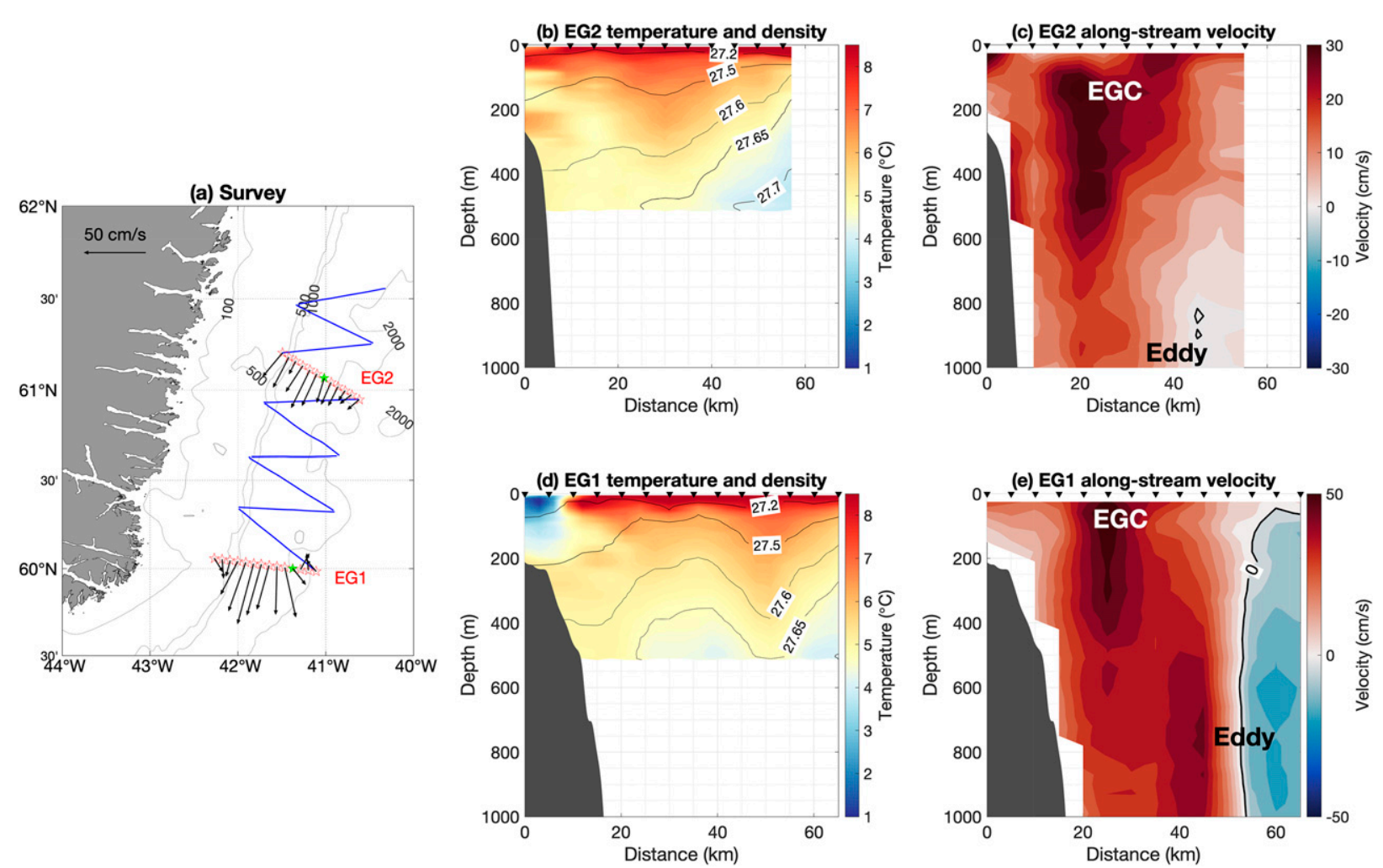

FIG. 10. Results from the EGC survey performed during the July 2020 OSNAP mooring cruise. (a) Map of the survey, where blue lines indicate ADCP sections, and red stars mark the stations of the two hydrographic sections. The two green stars indicate the center of the EG1 and EG2 eddies. Vectors are depth-mean velocity vectors from 0 to $1000 \mathrm{~m}$. The bathymetry is from ETOPO2. (b) Temperature (color) overlain by isopycnals (contours; $\mathrm{kg} \mathrm{m}^{-3}$ ) for the EG2 transect. The bathymetry is shown in gray (from the multibeam echosounder on R/V Neil Armstrong), and inverted triangles indicate the locations of the CTD stations. (c) Along-stream velocity from the 38-kHz ADCP for the EG2 transect. (d) As in (b), but for the EG1 transect. (e) As in (c), but for the EG1 transect. Note that the hydrographic casts extend to $500 \mathrm{~m}$, while the ADCP coverage reaches $1000 \mathrm{~m}$.

recirculation transport of $1.2 \pm 0.2 \mathrm{~Sv}$ using the gridded product described in section 2a. Following Pacini et al. (2020), we define NEADW as water more saline than 34.92 and denser than $27.74 \mathrm{~kg} \mathrm{~m}^{-3}$, and DSOW as water fresher than 34.92 and denser than $27.8 \mathrm{~kg} \mathrm{~m}^{-3}$. These definitions account for the reduction in density of NEADW through entrainment along its pathway around the subpolar gyre.

As discussed in section $3 \mathrm{~b}$, each cyclone is associated with an anomalous lens of overflow water at the base of the feature. This can be seen in the composite cyclone of Fig. 6, as well as for individual features propagating past the array. Shown in Fig. 9 is a depth versus time plot of along-stream velocity, cross-stream velocity, and temperature over a three-month period (September-November 2014), where the passage of cyclones is indicated along the top. All but one of the cold anomalies at depth (between 1200 and $2000 \mathrm{~m}$ ) were associated with an identified cyclone.

We assess the influence of the eddies on the transport by considering only the centered cyclones at LS6. This is because the core propagation velocity of noncentered features will be misrepresented by the mooring, since some of the azimuthal flow will be folded into the alongstream transport and the mooring could sample outside the region of core propagation.
The results are presented in Table 2, where only the water within the boundary current is considered (i.e., excluding the recirculation gyre). The first column is the 4-yr mean transport of the specified component of the boundary current, discussed in detail in Pacini et al. (2020). When the 26 centered cyclones identified and described in section $3 b(2)$ are considered, it indicates that the cyclonic eddies enhance the total transport of the boundary current by $2.8 \mathrm{~Sv}$. Broken down by water mass, $0.8 \mathrm{~Sv}$ of this increase is found in the DSOW, while the transport of NEADW increases by $1.1 \mathrm{~Sv}$. Hence, the overflow water transport is enhanced by $1.9 \mathrm{~Sv}$ over that of noneddy periods, a $19 \%$ increase. (When considering the traditional definition of overflow water, $\rho>27.8 \mathrm{~kg} \mathrm{~m}^{-3}$, the increase is $1.4 \mathrm{~Sv}$ or $18 \%$ ).

von Appen et al. (2014) estimated that the DSOW cyclones enhance the transport of overflow waters (denser than $27.74 \mathrm{~kg} \mathrm{~m}^{-3}$ ) by $0.7-1.2 \mathrm{~Sv}$ at the DS mooring array south of Denmark Strait, seemingly consistent with our result. However, when restricting their density criterion to $27.8 \mathrm{~kg} \mathrm{~m}^{-3}$, they calculate an increase in DSOW transport of $0.01-0.26 \mathrm{~Sv}$ due to the cyclones, significantly less than that measured here. It is worth noting that the CTD profilers on their moorings did not function when an eddy center passed close to a mooring (due to the significant 
mooring blowdown). Hence, their transport estimates are biased low by not measuring the full extent of the dense water lens. This makes a transport comparison between our site and the DS array problematic. Interestingly, most of the features measured at the DS array were located near the 900-m isobath, while the vast majority of cyclones detected at both OSNAP arrays were near the $2000-\mathrm{m}$ isobath. It is plausible that these are the same train of cyclones since the eddies move downslope as they progress equatorward (Bruce 1995). In particular, Bruce (1995) deduces a descent rate of $2.3 \mathrm{~m} \mathrm{~km}^{-1}$ from satellite SST imagery, and von Appen et al. (2014) deduce a downslope motion of $2.7 \mathrm{~m} \mathrm{~km}^{-1}$. Integrated over the $750 \mathrm{~km}$ between the DS array and OSNAP EG, this suggests the cyclones would descend from $900 \mathrm{~m}$ to approximately $2800 \mathrm{~m}$ by the time they reach the OSNAP EG array (where they are sampled at $2000 \mathrm{~m}$ ). While this predicted descent is somewhat larger than the actual descent observed, it is important to note that the descent rate, which is a function of local topography, translational velocity of the feature, and background alongand cross-stream velocity, likely changes along the feature's trajectory. There were also a significant number of cyclones sampled deeper on the continental slope at the DS array, extending to nearly $1600 \mathrm{~m}$ (von Appen et al. 2014). We saw no such offshore spread of cyclones at the OSNAP WG array, suggesting that these deeper features did not progress around Cape Farewell.

\section{d. Synoptic realization of cyclones from shipboard data}

High-resolution hydrographic surveys of the boundary current east and west of Cape Farewell have been performed during each of the OSNAP mooring turnaround cruises (2014, 2016, 2018, and 2020; e.g., Lin et al. 2018). Notably, during three of these four cruises at least one middepth intensified cyclonic eddy, transporting enhanced overflow water at depth, was sampled. During the 2020 cruise, a synoptic survey of the EGC was carried out over a period of $56 \mathrm{~h}$ (Fig. 10a). Shipboard ADCP data were collected along each of the lines, including measurements from the $38-\mathrm{kHz}$ instrument that extended to $1000 \mathrm{~m}$, while CTD stations extending to 500-m depth were occupied on two of them (the goal was to carry out the velocity survey quickly, with limited hydrographic coverage). As it happens, on both of the CTD lines we sampled a DSOW cyclone.

These synoptic crossings of cyclones are consistent with the individual and composite features observed at the OSNAP EG and WG arrays. Shown in Fig. 10 are the temperature and along-stream velocity vertical sections for both transects. The southern cyclone, sampled at transect EG1 (Figs. 10d,e) was sampled first. In this realization the surface-intensified EGC was flowing southward (order $50 \mathrm{~cm} \mathrm{~s}^{-1}$ ) associated with upward-sloping isopycnals extending offshore of the shelf break (Figs. 10d,e). Seaward of this, the isopycnals plunge $200 \mathrm{~m}$ and then rebound over a $20-\mathrm{km}$ range, indicating the top portion of a cyclonic feature with a radius of $\sim 10 \mathrm{~km}$. This is corroborated by the ADCP data, which extend deeper than the CTD data and reveal a symmetric region of enhanced flow centered near $800 \mathrm{~m}$ (where we would expect to see the isopycnals pinching if the hydrographic coverage extended this deep). The velocities are directed strongly to the south on the onshore side of the bowling isopycnals and to the north on the offshore side. This is consistent with our observations of DSOW cyclones at the LS6 mooring (Fig. 6), suggesting that this transect sliced the eddy close to its center.

The EG2 transect did not sample through the core of the northern cyclone, as evidenced by the discrepancy between its northward and southward flow (the velocity at the offshore side of the feature was barely reversed; Fig. 10c). The bowling of the isopycnals was much less pronounced, again consistent with the notion that the transect did not pass through the center of the feature. The isopycnal bowling was closer to the shelf break than for the EG1 transect, indicating that the cyclone was situated closer to the EGC than the feature to the south. Again, the cyclonic flow measured by the ADCP was situated directly below the bowling isopycnals, where the pinching of isopycnals of a cyclonic feature is expected. The shallow signature of the cyclone is masked by the EGC. While the northern cyclone is immediately adjacent to the EGC and the southern cyclone is $20 \mathrm{~km}$ offshore of the jet, the two features were propagating along the same isobath, $2030 \mathrm{~m}$, in line with the OSNAP EG and WG mooring data indicating that the majority of cyclones pass near the 2000-m isobath.

The OSNAP EG data revealed that a cyclonic feature goes by the array on average every 4.5 days. Is this consistent with the two cyclones sampled during our synoptic EGC survey? Using the background and core propagation velocity for the composite feature computed above, we assume that the two cyclones measured in the EGC survey are traveling southward at a speed of $u_{b}+u_{c, \max }$. This allows us to estimate the distance that the southern feature traveled between the time it was sampled and when the northern feature was sampled. Adding this to the distance between the two CTD sections gives the spacing between the cyclones, which, when divided by $u_{b}+$ $u_{c \text { max }}$, provides the temporal offset between the cyclones. Using $u_{b}=23 \mathrm{~cm} \mathrm{~s}^{-1}$ and $u_{c, \text { max }}=27 \mathrm{~cm} \mathrm{~s}^{-1}$ from the LS6 composite (Fig. 7a), this gives a separation time of 4.3 days, which agrees well with the value of 4.5 days deduced from the OSNAP EG mooring data.

\section{Discussion and conclusions}

Using four years of mooring data from the OSNAP WG mooring array, abundant cyclonic eddies have been observed throughout the length of the deployment. These features have not been described in the Labrador Sea prior to this study, either from an observational or modeling perspective. The features are middepth intensified, have no apparent seasonality in presence, can kinematically trap water, and are associated with a $2.8 \mathrm{~Sv}$ increase in boundary current transport, $1.9 \mathrm{~Sv}$ of which corresponds to overflow waters. Most of the features were detected by the mooring situated near the $2000 \mathrm{~m}$ isobath. A composite centered eddy was constructed for this site, revealing the structure and relevant length scales of these features. On average they have a radius of $9 \pm 1 \mathrm{~km}$, core propagation velocity of $27 \pm 8 \mathrm{~cm} \mathrm{~s}^{-1}$, and maximum azimuthal velocity of $24 \pm 0.6 \mathrm{~cm} \mathrm{~s}^{-1}$. 
These same features are also found upstream at the OSNAP EG mooring array. Their kinematic and hydrographic properties, as revealed by the mooring arrays and a synoptic shipboard survey, indicate that they are downstream manifestations of DSOW cyclones, which are middepth-intensified features formed by mesoscale variability in Denmark Strait. von Appen et al. (2014) reported that these features occur every 2 days at a mooring array $280 \mathrm{~km}$ south of Denmark Strait at the 900-m isobath, while the OSNAP EG array measures them every 4.5 days at the $2000-\mathrm{m}$ isobath and the OSNAP WG array samples them every 7.6 days, also near the 2000-m isobath. Thus, not all DSOW cyclones are able to reach the OSNAP EG array, and fewer still are able to round Cape Farewell into the Labrador Sea. This leads us to hypothesize that the remainder of the eddies either dissipate, are shed into the interior Irminger Sea, or are retroflected at Cape Farewell along with part of the mean EGC/DWBC.

The equatorward flow of dense water constitutes the lower limb of the AMOC, and this study has revealed that DSOW cyclones in the Labrador Sea contribute significantly to the export of overflow water (a $19 \%$ increase at OSNAP WG during cyclonic activity). Using repeat occupations of the AR7W section across the Labrador Sea, Pickart and Spall (2007) observed increased variance of the boundary current near the $2000 \mathrm{~m}$ isobath along the west coast of Greenland. While the authors speculated that this variability is driven by bottomtrapped topographic Rossby waves, it is possible that the deduced variability can be attributed to the presence and propagation of DSOW cyclones (see Fig. 3b, Pickart and Spall 2007). Given the role of the Labrador Sea as a site for deep convection, it is critical that we understand the variability of the boundary current system encircling the sea and how this could affect the interior stratification. Now that these features have been discovered, we need to understand how they influence the boundary current and what role they might play in transporting heat and freshwater into the interior of the basin - and ultimately how they dissipate. This must be factored into modeling studies in order to properly simulate and quantify the overturning in the Labrador Sea.

Acknowledgments. The authors thank the captain and crew of the R/V Knorr and R/V Neil Armstrong for the success of the OSNAP deployment and recovery cruises. John Kemp, Jim Ryder, Brian Hogue, Andrew Davies, and Rick Trask designed, fabricated, and deployed the moorings and instruments. Leah McRaven processed the shipboard CTD data and Frank Bahr processed the shipboard ADCP data. We would like to acknowledge the two anonymous reviewers whose input substantially improved the paper. A. P. and R. S. P. were funded by National Science Foundation Grants OCE-1259618 and OCE-1756361. I. L. B. and F. S. were funded by National Science Foundation Grants OCE-1258823 and OCE-1756272. N. P. H. was supported by the Natural Environment Research Council U.K. OSNAP program (NE/K010875/1 and NE/K010700/1). M. A. S. was supported by NSF Grants OCE-1558742 and OPP-1822334.

Data availability statement. The calibrated mooring and hydrographic data are available at www.o-snap.org. Specifically, the 2014-2016 OSNAP WG data can be found at https://doi.org/ 10.7924/r4fj2dr7k and the 2016-18 OSNAP WG data can be found at https://doi.org/10.35090/fz80-6c32. The OSNAP EG data can be found at https://doi.org/10.7924/r4fb50z9b, and the U.K. M1 mooring data can be found at https://doi.org/10.5285/ 6cb6dc0c-7bed-3ca4-e053-6c86abc0b9f0.

\section{REFERENCES}

Almansi, M., T. W. N. Haine, R. S. Pickart, M. G. Magaldi, R. Gelderloos, and D. Mastropole, 2017: High-frequency variability in the circulation and hydrography of the Denmark Strait overflow from a high-resolution numerical model. J. Phys. Oceanogr., 47, 2999-3013, https://doi.org/10.1175/JPO-D-170129.1.

,-- R. Gelderloos, and R.S. Pickart, 2020: Evolution of Denmark Strait overflow cyclones and their relationship to overflow surges. Geophys. Res. Lett., 47, e2019GL086759, https://doi.org/10.1029/2019GL086759.

Bosse, A., and Coauthors, 2016: Scales and dynamics of submesoscale coherent vortices formed by deep convection in the northwestern Mediterranean Sea. J. Geophys. Res. Oceans, 121, 7716-7742, https://doi.org/10.1002/2016JC012144.

Bracco, A., and J. Pedlosky, 2003: Vortex generation by topography in locally unstable baroclinic flows. J. Phys. Oceanogr., 33, 207-219, https://doi.org/10.1175/1520-0485(2003)033<0207: VGBTIL $>2.0$.CO;2.

,-- , and R. S. Pickart, 2008: Eddy formation near the west coast of Greenland. J. Phys. Oceanogr., 38, 1992-2002, https:// doi.org/10.1175/2008JPO3669.1.

Brandt, P., F. Schott, A. Funk, and C. Sena Martins, 2004: Seasonal to interannual variability of the eddy field in the Labrador Sea from satellite altimetry. J. Geophys. Res., 109, C02028, https:// doi.org/10.1029/2002JC001551.

Bruce, J. G., 1995: Eddies southwest of the Denmark Strait. DeepSea Res., 42, 13-29, https://doi.org/10.1016/0967-0637(94)00040-Y.

Cessi, P., and C. L. Wolfe, 2013: Adiabatic eastern boundary currents. J. Phys. Oceanogr., 43, 1127-1149, https://doi.org/ 10.1175/JPO-D-12-0211.1.

Chanut, J., B. Barnier, W. Large, L. Debreu, T. Penduff, J. M. Molines, and P. Mathiot, 2008: Mesoscale eddies in the Labrador Sea and their contribution to convection and restratification. J. Phys. Oceanogr., 38, 1617-1643, https://doi.org/ 10.1175/2008JPO3485.1.

Clarke, R. A., and J. C. Gascard, 1983: The formation of Labrador Sea Water. Part I: Large-scale processes. J. Phys. Oceanogr., 13, 1764-1778, https://doi.org/10.1175/1520-0485(1983)013<1764: TFOLSW $>2.0 . C O ; 2$.

de Jong, M. F., A. S. Bower, and H. H. Furey, 2014: Two years of observations of warm-core anticyclones in the Labrador Sea and their seasonal cycle in heat and salt stratification. J. Phys. Oceanogr., 44, 427-444, https://doi.org/10.1175/JPOD-13-070.1.

$\longrightarrow,-$, and $\longrightarrow, 2016$ : Seasonal and interannual variations of Irminger ring formation and boundary-interior heat exchange in FLAME. J. Phys. Oceanogr., 46, 1717-1734, https://doi.org/ 10.1175/JPO-D-15-0124.1.

Dickson, R. R., and J. Brown, 1994: The production of North Atlantic Deep Water: Sources, rates and pathways. J. Geophys. Res., 99, 12 319-12 341, https://doi.org/10.1029/94JC00530.

Eden, C., and C. Böning, 2002: Sources of eddy kinetic energy in the Labrador Sea. J. Phys. Oceanogr., 32, 3346-3363, https://doi.org/ 10.1175/1520-0485(2002)032<3346:SOEKEI >2.0.CO;2. 
Flierl, G., 1981: Particle motions in large-amplitude wave fields. Geophys. Astrophys. Fluid Dyn., 18, 39-74, https://doi.org/ 10.1080/03091928108208773.

Frajka-Williams, E., P. B. Rhines, and C. C. Eriksen, 2009: Physical coontrols and mesoscale variability in the Labrador Sea spring phytoplankton bloom observed by Seaglider. Deep-Sea Res. I, 56, 2144-2161, https://doi.org/10.1016/j.dsr.2009.07.008.

Gascard, J. C., and R. A. Clarke, 1983: The formation of Labrador Sea Water. Part II. Mesoscale and smaller-scale processes. J. Phys. Oceanogr., 13, 1779-1797, https://doi.org/10.1175/ 1520-0485(1983)013<1779:TFOLSW $>2.0$. CO;2.

Gelderloos, R., C. A. Katsman, and A. S. S. Drijfhout, 2011: Assessing the roles of three eddy types in restratifying the Labrador Sea after deep convection. J. Phys. Oceanogr., 41, 2102-2119, https://doi.org/10.1175/JPO-D-11-054.1.

Hátún, H., C. Eriksen, P. Rhines, and J. Lilly, 2007: Buoyant eddies entering the Labrador Sea observed with gliders and altimetry. J. Phys. Oceanogr., 37, 2838-2854, https://doi.org/10.1175/ 2007JPO3567.1.

Heywood, K. J., E. L. McDonagh, and M. A. White, 1994: Eddy kinetic energy of the North Atlantic subpolar gyre from satellite altimetry. J. Geophys. Res., 99, 22 525-22 539, https:// doi.org/10.1029/94JC01740.

Hogg, N. G., 1986: On the correction of temperature and velocity time series for mooring motion. J. Atmos. Oceanic Technol., 3, 204-214, https://doi.org/10.1175/1520-0426(1986)003<0204: OTCOTA $>2.0 . \mathrm{CO} ; 2$.

_ 1991: Mooring motion corrections revisited. J. Atmos. Oceanic Technol., 8, 289-295, https://doi.org/10.1175/1520-0426(1991) 008<0289:MMCR > 2.0.CO;2.

Holliday, N. P., A. Meyer, S. Bacon, S. Alderson, and B. de Cuevas, 2007: The retroflection of part of the East Greenland Current at Cape Farewell. Geophys. Res. Lett., 34, L07609, https:// doi.org/10.1029/2006GL029085.

— S. Bacon, J. T. Allen, and E. L. McDonagh, 2009: Circulation and transport in the western boundary currents at Cape Farewell, Greenland. J. Phys. Oceanogr., 39, 1854-1870, https://doi.org/ 10.1175/2009JPO4160.1.

Hopkins, J. E., N. P. Holliday, D. Rayner, L. Houpert, I. Le Bras, F. Straneo, C. Wilson, and S. Bacon, 2019: Transport variability of the Irminger Sea deep western boundary current from a mooring array. J. Geophys. Res. Oceans, 124, 32463278, https://doi.org/10.1029/2018JC014730.

Katsman, C., M. Spall, and R. S. Pickart, 2004: Boundary current eddies and their role in the restratification of the Labrador Sea. J. Phys. Oceanogr., 34, 1967-1983, https://doi.org/10.1175/ 1520-0485(2004)034<1967:BCEATR >2.0.CO;2.

Kawasaki, T., and H. Hasumi, 2014: Effect of freshwater from the West Greenland Current on the winter deep convection in the Labrador Sea. Ocean Modell., 75, 51-64, https://doi.org/ 10.1016/j.ocemod.2014.01.003.

Khatiwala, S., and Coauthors, 2013: Global ocean storage of anthropogenic carbon. Biogeosciences, 10, 2169-2191, https:// doi.org/10.5194/bg-10-2169-2013.

Lazier, J. R. N., and D. G. Wright, 1993: Annual velocity variations in the Labrador Current. J. Phys. Oceanogr., 23, 659-678, https:// doi.org/10.1175/1520-0485(1993)023<0659:AVVITL >2.0.CO;2.

Le Bras, I. A. A., F. Straneo, J. Holte, and N. P. Holliday, 2018: Seasonality of freshwater in the east Greenland current system from 2014 to 2016. J. Geophys. Res. Oceans, 123, 8828-8848, https://doi.org/10.1029/2018JC014511.

,,--- M. F. de Jong, and N. P. Holliday, 2020: Rapid export of waters formed by convection near the Irminger Sea's western boundary. Geophys. Res. Lett., 47, e2019GL085989, https://doi.org/10.1029/2019GL085989.

Lee, A., and D. Ellett, 1965: On the contribution of overflow water from the Norwegian Sea to the hydrographic structure of the North Atlantic Ocean. Deep-Sea Res., 12, 129-142, https:// doi.org/10.1016/0011-7471(65)90019-7.

Lilly, J. M., and P. B. Rhines, 2002: Coherent eddies in the Labrador Sea observed from a mooring. J. Phys. Oceanogr., 32, 585-598, https://doi.org/10.1175/1520-0485(2002)032<0585: CEITLS $>2.0 . \mathrm{CO} ; 2$.

- - - F. Schott, K. Lavender, J. Lazier, U. Send, and E. D'Asaro, 2003: Observations of the Labrador Sea eddy field. Prog. Oceanogr., 59, 75-176, https://doi.org/10.1016/ j.pocean.2003.08.013.

, M. Visbeck, R. Davis, J. R. N. Lazier, F. Schott, and D. Farmer, 1999: Observing deep convection in the Labrador Sea during winter 1994/1995. J. Phys. Oceanogr., 29, 2065-2098, https://doi.org/10.1175/1520-0485(1999)029<2065:ODCITL > 2.0.CO;2.

Lin, P., R. S. Pickart, D. J. Torres, and A. Pacini, 2018: Evolution of the freshwater coastal current at the southern tip of Greenland. J. Phys. Oceanogr., 48, 2127-2140, https://doi.org/ 10.1175/JPO-D-18-0035.1.

Martin, A., and K. Richards, 2001: Mechanisms for vertical nutrient transport within a North Atlantic mesoscale eddy. Deep-Sea Res. II, 48, 757-773, https://doi.org/10.1016/S0967-0645(00)00096-5.

Mastropole, D., R. S. Pickart, H. Valdimarsson, K. Våge, K. Jochumsen, and J. B. Girton, 2017: On the hydrography of Denmark Strait. J. Geophys. Res. Oceans, 122, 306-321, https://doi.org/10.1002/ 2016JC012007.

McWilliams, J. C., 1985: Submesoscale, coherent vortices in the ocean. Rev. Geophys., 23, 165-182, https://doi.org/10.1029/ RG023i002p00165.

Nof, D., 1983: The translation of isolated cold eddies on a sloping bottom. Deep-Sea Res., 30, 171-182, https://doi.org/10.1016/ 0198-0149(83)90067-5.

Pacini, A., and Coauthors, 2020: Mean conditions and seasonality of the west Greenland boundary current system near Cape Farewell. J. Phys. Oceanogr., 50, 2849-2871, https://doi.org/ 10.1175/JPO-D-20-0086.1.

Pawlowicz, R., B. Beardsley, and S. Lentz, 2002: Classical tidal harmonic analysis including error estimates in MATLAB using T-TIDE. Comput. Geosci., 28, 929-937, https://doi.org/ 10.1016/S0098-3004(02)00013-4.

Pedlosky, J., 2003: Waves in the Ocean and Atmosphere: Introduction to Wave Dynamics. Springer, $264 \mathrm{pp}$.

Pickart, R. S., 1992: Water mass components of the North Atlantic deep western boundary current. Deep-Sea Res. I, 39, 1553-1572, https://doi.org/10.1016/0198-0149(92)90047-W.

_, and M. A. Spall, 2007: Impact of Labrador Sea convection on the North Atlantic meridional overturning circulation. J. Phys. Oceanogr., 37, 2207-2227, https://doi.org/10.1175/JPO3178.1.

- D. J. Torres, and R. A. Clarke, 2002: Hydrography of the Labrador Sea during active convection. J. Phys. Oceanogr., 32, 428-457, https://doi.org/10.1175/1520-0485(2002)032<0428: HOTLSD $>2.0 . \mathrm{CO} ; 2$

$\longrightarrow,-$, and P. S. Fratantoni, 2005: The East Greenland spill jet. J. Phys. Oceanogr., 35, 1037-1053, https://doi.org/10.1175/ JPO2734.1

Prater, M., 2002: Eddies in the Labrador Sea as observed by profiling RAFOS floats and remote sensing. J. Phys. Oceanogr., 32, 411-427, https://doi.org/10.1175/1520-0485(2002)032<0411: EITLSA $>2.0 . \mathrm{CO} ; 2$. 
Rhein, M., and Coauthors, 2002: Labrador Sea Water: Pathways, CFC inventory, and formation rates. J. Phys. Oceanogr., 32, 648-665, https://doi.org/10.1175/1520-0485(2002)032<0648: LSWPCI $>2.0 . C O ; 2$.

Rieck, J. K., C. W. Böning, and K. Getzlaff, 2019: The nature of eddy kinetic energy in the Labrador Sea: Different types of mesoscale eddies, their temporal variability and impact on deep convection. J. Phys. Oceanogr., 49, 2075-2094, https:// doi.org/10.1175/JPO-D-18-0243.1.

Rudels, B., E. Fahrbach, J. Meincke, G. Budéus, and P. Ericksson, 2002: The East Greenland Current and its contribution to the Denmark Strait overflow. ICES J. Mar. Sci., 59, 1133-1154, https://doi.org/10.1006/jmsc.2002.1284.

Rykova, T., F. Straneo, and A. S. Bower, 2015: Seasonal and interannual variability of the west Greenland current system in the Labrador Sea in 1993-2008. J. Geophys. Res. Oceans, 120, 1318-1332, https://doi.org/10.1002/2014JC010386.

Smith, W. H. F., and P. Wessel, 1990: Gridding with continuous curvature splines in tension. Geophysics, 55, 293-305, https:// doi.org/10.1190/1.1442837.

Spall, M. A., 2004: Boundary currents and water mass transformation in marginal seas. J. Phys. Oceanogr., 34, 1197-1213, https:// doi.org/10.1175/1520-0485(2004)034<1197:BCAWTI>2.0.CO;2.

_ 2010: Dynamics of downwelling in an eddy-resolving convective basin. J. Phys. Oceanogr., 40, 2341-2347, https://doi.org/ 10.1175/2010JPO4465.1.

— The PV outflow hypothesis. J. Phys. Oceanogr., 28, 1598-1623, https://doi.org/10.1175/1520-0485(1998)028<1598:MVIDST> 2.0.CO;2.

— gyre example. J. Phys. Oceanogr., 31, 810-826, https://doi.org/ 10.1175/1520-0485(2001)031<0810:WDDWSA $>2.0$. CO; 2 .

— stable flows. J. Phys. Oceanogr., 38, 1267-1277, https://doi.org/ 10.1175/2007JPO3906.1.

— R. S. Pickart, P. Lin, H. Valdimarsson, T. W. N. Haine, and M. Almansi, 2019: Frontogenesis and variability in Denmark
Strait and its influence on overflow water. J. Phys. Oceanogr., 49, 1889-1904, https://doi.org/10.1175/JPO-D-19-0053.1.

Sutherland, D. A., R. S. Pickart, E. P. Jones, K. Azetsu-Scott, A. J. Eert, and J. Ólafsson, 2009: Freshwater composition of the waters off southEast Greenland and their link to the Arctic Ocean. J. Geophys. Res., 114, C05020, https://doi.org/10.1029/ 2008JC004808.

Sy, A., M. Rhein, J. R. N. Lazier, K. P. Koltermann, J. Meincke, A. Putzka, and M. Bersch, 1997: Surprisingly rapid spreading of newly formed intermediate waters across the North Atlantic Ocean. Nature, 386, 675-679, https://doi.org/10.1038/386675a0.

Takahashi, T., and Coauthors, 2009: Climatological mean and decadal change in surface ocean $\mathrm{pCO}_{2}$, and net sea-air $\mathrm{CO}_{2}$ flux over the global oceans. Deep-Sea Res. II, 56, 554-577, https:// doi.org/10.1016/j.dsr2.2008.12.009.

Talley, L. D., and M. S. McCartney, 1982: Distribution and circulation of Labrador Sea Water. J. Phys. Oceanogr., 12, 1189-1205, https://doi.org/10.1175/1520-0485(1982)012<1189:DACOLS> 2.0.CO;2.

Tanhua, T., K. A. Olsson, and E. Jeansson, 2005: Formation of Denmark Strait Overflow Water and its hydro-chemical composition. J. Mar. Syst., 57, 264-288, https://doi.org/10.1016/ j.jmarsys.2005.05.003.

The Lab Sea Group, 1998: The Labrador Sea Deep Convection Experiment. Bull. Amer. Meteor. Soc., 79, 2033-2058, https:// doi.org/10.1175/1520-0477(1998)079<2033:TLSDCE>2.0.CO;2.

von Appen, W., R. S. Pickart, K. Brink, and T. Haine, 2014: Water column structure and statistics of Denmark Strait Overflow Water cyclones. Deep-Sea Res. I, 84, 110-126, https://doi.org/ 10.1016/j.dsr.2013.10.007.

—, D. Mastropole, R. S. Pickart, H. Valdimarsson, S. Jónsson, and J. B. Girton, 2017: On the nature of the mesoscale variability in Denmark Strait. J. Phys. Oceanogr., 47, 567-582, https://doi.org/10.1175/JPO-D-16-0127.1.

Wolfe, C., and C. Cenedese, 2006: Laboratory experiments on eddy generation by a buoyant coastal current flowing over variable bathymetry. J. Phys. Oceanogr., 36, 395-411, https://doi.org/ 10.1175/JPO2857.1. 